\title{
The analytic hierarchy process with personalized individual semantics
}

\author{
Qiuxiang Zhou ${ }^{1}$, Yucheng Dong ${ }^{1}$, Hengjie Zhang ${ }^{2, *}$, Yuan Gao ${ }^{1}$ \\ ${ }^{1}$ Business School, Sichuan University, Chengdu 610065, China \\ ${ }^{2}$ Business School, Hohai University, Nanjing 211100, China \\ E-mails:qxzhou@stu.scu.edu.cn (Qiuxiang Zhou) \\ ycdong@scu.edu.cn (Yucheng Dong) \\ hengjiezhang@hhu.edu.cn (Hengjie Zhang) \\ gaoyuan1984@scu.edu.cn (Yuan Gao)
}

Received 25 July 2017

Accepted 22 December 2017

\begin{abstract}
Personalized individual semantics (PIS) is not unusual in our daily life, and it has an important influence on the final decision results in linguistic decision making. The analytic hierarchy process (AHP) has now become a popular decision tool because of its sound mathematical design and ease of applicability to real-world decision making problems. In the AHP, two formats of preference information are included: linguistic and numerical preference information. In order to implement the computation operation, the linguistic preference information is often transformed into the numerical preference information using a fixed numerical scale function (e.g., the Saaty scale). However, the PIS is not taken into account by the AHP with a fixed numerical scale function. Therefore, this study proposes a novel AHP framework with the PIS, and develops a consistency-driven methodology to minimize the inconsistency level of numerical preference information that transformed from linguistic preference information. In the proposed AHP framework, a two-stage based optimization model is designed to deal with the PIS, and the proposed optimization models are converted into some linear programming models that can be easily solved. Finally, a practical example and a comparison experiment are proposed to verify the validity of our proposal.
\end{abstract}

Keywords: Analytic hierarchy process (AHP), personalized individual semantics (PIS), numerical scale, the 2-tuple linguistic model, consistency-driven methodology.

\section{Introduction}

The analytic hierarchy process (AHP) that initialized by Saaty (1980) provides decision makers with a way to transform subjective judgments into objective measures[38]. Due to its mathematical simplicity and flexibility, AHP has been a favorite decision tool for research in many fields [43], such as manufacture, politics and economy, power and energy, education, and

\footnotetext{
* Corresponding author
}

medicine. In general, the implementation of the AHP includes the following steps: (1) construct a decision-making problem in a hierarchy as goal, criteria, sub-criteria, and decision alternatives; (2) provide linguistic preference information (i.e., linguistic pairwise comparison matrices (LPCMs), or linguistic preference relations) at each level of the hierarchy structure; (3) transform the linguistic preference information into numerical preference information (i.e., numerical pairwise comparison matrices (NPCMs)) using a numerical scale function (i.e., the Saaty scale); 
(4) check the consistency of numerical preference information; (5) obtain the local priority vectors corresponding to the criteria or sub-criteria applying the given prioritization method (e.g., Eigenvalue method); (6) obtain the global priority vectors of alternatives by synthesizing the local priority vectors. The detailed information of the AHP can be found in [13, 38, 40].

By analyzing the implementation process of the AHP, we find that the validity of which depends on the selection of numerical scale function in step 3. This issue has been investigated by several scholars, and several numerical scale functions have been proposed, such as the Saaty scale function [38], the Ma-Zheng scale function [30], the geometrical scale function [21, 26, 29], and the Salo Hämäläinen scale function [37]. However, there are still some disputes on which numerical scale function is better. Harker and Vargas [23] argued that the choice of numerical scale function in the AHP is an open problem.

The selection of numerical scale in the AHP is closely related to the computing with words (CWW). In the field of CWW, there is a fact that the same word usually means different things for different experts ([31, 32]). For example, two experts may all provide their comments "good" on a project in the project review process. However, the term "good" often refers to different scores for these two experts when they grade the project on a scale of 0 to 100 , one expert might give 80 and another give 90 . There are two mainstreams in the literature to deal with this issue: (1) the type-2 fuzzy sets [31], (2) the multi-granular linguistic models [16, $34,45,50]$. Despite these approaches are quite useful, they do not present the specific semantics for each expert. To overcome this problem, Li et al. [27] proposed an optimization-based model to deal with personalized individual semantics (PIS for short) in the linguistic decision making.

Based on the above analysis, there is no doubt that the PIS will occur in the AHP, and it has a very important influence on the final decision results. To our knowledge, the PIS is rarely considered by the existing literature except two works $[25,35]$. In $[25,35]$, the existence of PIS in the AHP has been demonstrated by using empirical study. However, an effective way to deal with the PIS in the AHP is not provided in $[25,35]$.

The main purpose of this study is to propose a novel AHP framework: the AHP framework with the PIS. In the novel AHP, the most important step is the design of the transformation method between the linguistic and numerical preference information. To support the novel framework, we devise a consistency-driven approach that minimizes the consistency index of the transformed numerical preference information. This approach is based on a basic idea that if linguistic preference information is of acceptable consistency, then the consistency level of the transformed numerical preference information should be as better as possible, due to the fact that both the linguistic and numerical preference information are associated with the same expert. Specifically, we propose a two-stage based optimization model to address the PIS in the AHP. The first-stage optimization model is used to generate the individual numerical scales by maximizing the consistency level of the transformed numerical preference information, and the second-stage optimization model is utilized to further optimize the optimal solutions derived from the first-stage model. In addition, both the optimization models in first and second stages are converted into linear programming models that can be easily solved.

The remainder of this study is arranged as follows. Section 2 introduces the 2-tuple linguistic model, numerical scales and the AHP with a fixed numerical scale function. Section 3 designs a novel AHP framework with the PIS. Next, Section 4 presents the consistency-driven approach to deal with the PIS in the AHP. Following this, a practical example is used to illustrate the application process of our proposal. Section 6 gives a comparative study. Finally, Section 7 concludes the study and discusses the future research directions.

\section{Preliminaries}

In this section, the fundamental knowledge regarding the 2-tuple linguistic model, preference relations, numerical scales, and the AHP with a fixed numerical scale, are briefly described.

\subsection{The 2-tuple linguistic model and preference relations}

(1) The 2-tuple linguistic model Let $S=\left\{s_{i} \mid i=0,1,2, \ldots, g\right\}$ be a linguistic term set, in which the number of linguistic terms is odd (i.e., $\mathrm{g}+1)$. The term $s_{i}$ denotes a possible value for a 
linguistic variable, and the following two conditions should be satisfied [15].

(i) If $i>j$, then $s_{i}>s_{j}$.

(ii) We have $\operatorname{Neg}\left(s_{i}\right)=s_{j}$ such that $j=g-i$, where Neg denotes a negation operator.

The 2-tuple linguistic model that proposed by Herrera and Martínez [24] is a popular model for computing with words. Let $S$ be as above. In the 2-tuple linguistic model, a 2-tuple $\left(s_{i}, \alpha\right)$ is utilized to express the equivalent information to $\beta \in[0, g]$ :

$\Delta:[0, g] \rightarrow S \times[-0.5,0.5)$, where

$$
\Delta(\beta)=\left(s_{i}, \alpha\right), \text { with }\left\{\begin{array}{l}
s_{i}, i=\operatorname{round}(\beta) \\
\alpha=\beta-i, \alpha \in[-0.5,0.5)
\end{array}\right.
$$

where $\Delta$ is a one to one mapping function. Let $\bar{S}=\left\{\left(s_{i}, \alpha\right) \mid s_{i} \in S, \alpha \in[-0.5,0.5)\right\} \quad$ be the 2-tuple linguistic term set. In addition, $\Delta$ has an inverse function $\Delta^{-1}: \bar{S} \rightarrow[0, g]$ with $\Delta^{-1}\left(s_{i}, \alpha\right)=i+\alpha$.

(2) Preference relations

Let $X=\left\{x_{1}, x_{2}, \ldots, x_{n}\right\}$ be a set of alternatives. During the decision making process, preference relations (e.g. [7, 28, 22]) are very useful tools for decision makers to express their preferences over $X$. In particular, linguistic and multiplicative preference relations are widely adopted in the decision making. In the following, we introduce these two types of preference relations.

Definition 1 [1, 12]: The linguistic preference relation is represented by a matrix $L=\left(l_{i j}\right)_{n \times n}$, in which the element $l_{i j} \in S$ signifies the preference intensity of alternative $x_{i}$ over $x_{j}$. The linguistic preference relation $L=\left(l_{i j}\right)_{n \times n}$ is often assumed to be reciprocal, that is $l_{i j}=\operatorname{Neg}\left(l_{j i}\right)$ for $i, j=1, \ldots, n$.

Definition 2 [40, 46]: The multiplicative preference relation is denoted using a matrix $A=\left(a_{i j}\right)_{n \times n}$, in which $a_{i j}>0$ signifies the important degree (or preference intensity) of alternative $x_{i}$ over $x_{j}$ and $a_{i j} \times a_{i i}=1$ for $i, j=1, \ldots, n$. If $a_{i t} \times a_{t j}=a_{i j}(\forall i, j, t=1,2, \ldots, n)$, then $A$ is considered as a completely consistent multiplicative preference relation.

\subsection{Numerical scales}

The numerical scale was developed by Dong et al. [19], which is utilized to convert linguistic information into numerical information.
Definition 3 [19]: Let $S$ be as before, and $R$ be the real number set. The numerical scale of $S$ is defined as a function: $N S: S \rightarrow R$, and we use $N S\left(s_{i}\right)$ to denote the numerical index of linguistic term $S_{i}$.

Moreover, the numerical scale of the 2-tuple linguistic information was also developed, which is defined as follows.

Definition 4 [19]: Let $S, \bar{S}$ and $N S$ be as above. The numerical scale function $\overline{N S}$ on $\bar{S}$ for $\left(s_{i}, \alpha\right) \in \bar{S}$, is defined as below:

$\overline{N S}\left(\left(s_{i}, \alpha\right)\right)=\left\{\begin{array}{l}N S\left(s_{i}\right)+\alpha\left(N S\left(s_{i+1}\right)-N S\left(s_{i}\right)\right), \quad \alpha \geq 0 \\ N S\left(s_{i}\right)+\alpha\left(N S\left(s_{i}\right)-N S\left(s_{i-1}\right)\right), \quad \alpha<0\end{array}\right.$

For simplification, $\overline{N S}$ will also be denoted as $N S$ throughout this study.

\subsection{Analytic hierarchy process}

This section introduces the basic framework of AHP, and the 2-tuple linguistic modeling for the AHP scale problem.

(1) The framework of AHP

Saaty [38] developed following steps for applying the AHP.

a) Establish the hierarchical structure

When using AHP to solve a decision problem, firstly, decision makers need to disassemble the problem into a hierarchy of more easily comprehended sub-problems. A hierarchical structure (shown as Fig. 1) is often composed by the following levels: goal level, criterion levels, and alternative level. In addition, there are subordinate relationships between the elements on two adjacent levels in the hierarchy.

Let $H_{k}(k=1, \ldots, m)$ be the $k$ th level of the given hierarchical structure. The top level (i.e., $H_{1}$ ) is

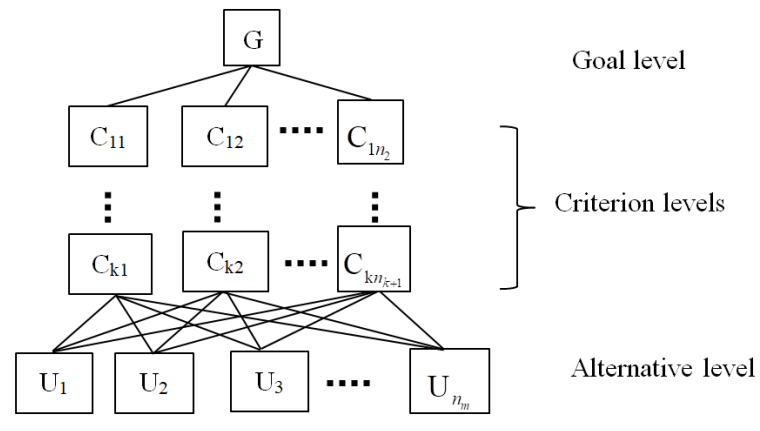

Fig. 1. The hierarchical structure. 
the goal level, the bottom level (i.e., $H_{m}$ ) is the alternative level, the others are criterion levels. Let $n_{k}$ $(k=1, \ldots, m) \quad$ be the number of elements (criteria/alternatives) in $H_{k}$. In particular, $n_{m}$ denotes the number of alternatives. Let $e_{k}^{z}\left(z=1, \ldots, n_{k}\right.$, $k=1, \ldots, m) \quad$ be the $z$ th element in $H_{k} ; n_{k}^{z}$ $\left(z=1, \ldots, n_{k}, k=1, \ldots, m-1\right)$ be the number of the elements in $H_{k+1}$ controlled by the element $e_{k}^{z}$; and $e_{i}^{k, z}\left(i=1, \ldots, n_{k}^{z}, \quad z=1, \ldots, n_{k}, k=1, \ldots, m-1\right) \quad$ be the $i$ th element controlled by the element $e_{k}^{z}$.

b) Make pairwise comparisons using AHP linguistic scale to obtain linguistic preference relations

Decision makers provide their linguistic preference information regarding criteria and alternatives corresponding to the parent element at the adjacent upper level. For the parent element $e_{k}^{z}\left(z=1, \ldots, n_{k}\right.$, $k=1, \ldots, m-1)$, decision makers use AHP linguistic term set to characterize the important degree between the element $e_{i}^{k, z}$ and $e_{j}^{k, z} \quad\left(i, j=1, \ldots, n_{k}^{z}\right)$, and then construct the LPCM $L_{k}^{z}=\left(l_{i j}^{k, z}\right)_{n_{z}^{k} \times n_{z}^{k}} \quad\left(z=1, \ldots, n_{k}\right.$, $k=1, \ldots, m-1)$.

c) Transform LPCMs into NPCMs using AHP numerical scale

In the traditional AHP, decision makers employ a fixed numerical scale (i.e., the Saaty scale) to transform the LPCMs $L_{k}^{z}$ into NPCMs $A_{k}^{z}=\left(a_{i j}^{k, z}\right)_{n \times n}\left(z=1, \ldots, n_{k}\right.$, $k=1, \ldots, m-1)$.

d) Employ a prioritization method to derive the local priority vectors of criteria and alternatives

By adopting a selected prioritization method, we can derive priority vectors $l p_{k}^{z}=\left(l p_{1}^{k, z}, \ldots, l p_{n_{k}^{z}}^{k, z}\right)^{T}$ $\left(z=1, \ldots, n_{k}, k=1, \ldots, m-1\right)$ from the NPCMs $A_{k}^{z}$. $l p_{i}^{k, z}\left(i=1, \ldots, n_{k}^{z}\right)$ represents the local priority of the element $e_{i}^{k, z}$ with respect to the element $e_{k}^{z}$, all of elements $e_{i}^{k, z}\left(i=1, \ldots, n_{k}^{z}\right)$ are in $H_{k+1}$ and controlled by the element $e_{k}^{z}$. For the elements in $H_{k+1}$ that aren't controlled by the element $e_{k}^{z}$, the local priorities are 0 . Then, we can obtain the local priority vector of all elements in $H_{k+1}$ with respect to the element $e_{k}^{z}$, defined as $\quad P_{k}^{z}=\left(p_{1}^{k, z}, \ldots, p_{n_{k+1}^{k, z}}^{k}\right)^{T} \quad\left(z=1, \ldots, n_{k} \quad\right.$, $k=1, \ldots, m-1), \quad p_{j}^{k, z}\left(j=1, \ldots, n_{k+1}\right) \quad$ represents the local priority of the element $e_{k+1}^{j}$ with respect to the element $e_{k}^{z}$.
To derive a priority vector from a NPCM $A=\left(a_{i j}\right)_{n \times n}$, the prioritization method is often used. There are several prioritization methods (e.g., [8, 9, 33, $38,39,41,49])$. In this paper, we adopt the Eigenvalue method proposed by Saaty [39], which is introduced below.

Let $\lambda$ and $p^{\prime}$ be the eigenvalue and eigenvector of matrix $A$, respectively, and they can be obtained by the following model:

$$
A p^{\prime}=\lambda p^{\prime}, e^{T} p^{\prime}=1,
$$

Saaty sets the principle eigenvector as the desired priority vector of $A$.

e) Consistency test

Consistency test is adopted to check whether the NPCMs are logical or not. If the NPCMs fail the consistency test, decision maker should adjust the corresponding LPCMs. There are many consistency improving approaches $[5,47]$. In particular, the consistency index ( CI ) based on the eigenvalue prioritization method proposed by Saaty [38] is calculated as below:

$$
\mathrm{CI}=\frac{\lambda_{\max }-n}{n-1}
$$

where $\lambda_{\max }$ and $n$ denote the maximum eigenvalue and the size of NPCM $A$, respectively.

Further, Saaty proposed the concept of consistency ratio, that is

$$
\mathrm{CR}=\frac{\mathrm{CI}}{\mathrm{RI}}
$$

where RI denotes the average value of $\mathrm{CI}$ obtained from a group of randomly generated NPCMs. In general, if $\mathrm{CR} \leq 0.1$, then the NPCM is considered as consistent. The RI values for different NPCM sizes ( $n$ ) are given in Table 1.

Table 1. Values of RI for different matrix size $(n)$

\begin{tabular}{llllllll}
\hline$n$ & 3 & 4 & 5 & 6 & 7 & 8 & 9 \\
\hline RI & 0.52 & 0.89 & 1.12 & 1.26 & 1.36 & 1.41 & 1.46 \\
\hline
\end{tabular}

In addition, there are several other approaches for measuring the consistency level of NPCMs (see [2, 3, 6, 14, 42]).

f) Synthesize the priority vectors to yield the global priority vector 
This process is to synthesize the local priority vectors with respect to all criteria to generate the global priority vectors. Further, we can obtain the ranking of the alternatives from the global priority vector at the alternative level.

$$
\text { Suppose that } \quad w^{k-1}=\left(w_{1}^{k-1}, w_{2}^{k-1}, \ldots, w_{n_{k-1}^{k-1}}\right)^{T}
$$
$(k=2,3, \ldots, m)$ is the global priority vector of the elements in $H_{k-1}$ with respect to the global goal. Laying out the local priority vectors of all elements in $H_{k}$ corresponding to the each element in $H_{k-1}$ into a matrix, defined as $P^{k}=\left(P_{k-1}^{1}, P_{k-1}^{2}, \ldots, P_{k-1}^{n_{k-1}}\right)$ $=\left(p_{i j}^{k}\right)_{n_{k} \times n_{k-1}}(k=2, \ldots, m)$, then the global priority vector of elements in $H_{k}$ can be obtained by,

$$
w^{k}=\left(w_{1}^{k}, w_{2}^{k}, \ldots, w_{n_{k-1}}^{k}\right)^{T}=P^{k} w^{k-1}
$$

or $\quad w_{i}^{k}=\sum_{j=1}^{k-1} p_{i j}^{k} \times w_{j}^{k-1}, i=1, \ldots, n ; k=2,3, \ldots, m$

Therefore, $w^{k}=P^{k} P^{k-1} \ldots w^{2}$ and $w^{2}=P^{2}=$ $P_{1}^{1}=\left(p_{1}^{1,1}, p_{2}^{1,1}, \ldots, p_{n_{2}}^{1,1}\right)^{T}$. The ranking of alternatives can be obtained according to $w^{m}$.

(2) 2-tuple linguistic modeling of the AHP scale problem

The scale in AHP is composed of AHP linguistic and numerical scales. Table 2 shows the Saaty's linguistic scale (see [40]).

Table 2. Linguistic part of the Saaty scale

\begin{tabular}{cl}
\hline Grade & AHP linguistic scale \\
\hline 1 & Equally important \\
2 & Weakly more important \\
3 & Moderately more important \\
4 & Moderately plus more important \\
5 & Strongly more important \\
6 & Strongly more important \\
7 & Demonstratedly more important \\
8 & Very, very Strongly more important \\
9 & Extremely more important \\
\hline
\end{tabular}

According to Saaty's linguistic scale, we define the following linguistic term set [12]:
$S^{\mathrm{AHP}}=\left\{s_{0}=\right.$ extremely less important,

$s_{1}=$ very very strongly less important,

$s_{2}=$ demonstratedly less important, $s_{3}=$ strongly plus less important, $s_{4}=$ strongly less important, $s_{5}=$ moderately plus less important, $s_{6}=$ moderately less important, $s_{7}=$ weakly less important, $s_{8}=$ equally important, $s_{9}=$ weakly more important, $s_{10}=$ moderately more important, $s_{11}=$ moderately plus more important, $s_{12}=$ strongly more important, $s_{13}=$ strongly plus more important, $s_{14}=$ demonstratedly more important, $s_{15}=$ very very strongly more important, $s_{16}=$ extremely more important $\}$

where $S_{i}(i=0,1,2, \ldots, 16)$ satisfies the characteristics of linguistic term set, and $\left\{s_{i}, s_{16-i}\right\} \quad(i=8,9, \ldots, 16)$ is associated with the $(i-7)$ th gradation of the Saaty's linguistic scale.

There are 17 numerical values in the AHP numerical scale, which are described below:

$$
\left\{\frac{1}{f_{i}}, f_{1}, f_{i}\right\}, i=2,3, \ldots, 9,
$$

where $f_{1}=1$ and $f_{i+1}>f_{i}>1$. The value of $f_{i}(i=1,2, \ldots, 9)$ is associated with the $i$ th gradation of the AHP linguistic scale. Naturally, there are different numerical scales when setting different values for $f_{i}(i=2,3, \ldots, 9)$ (e.g., [21, 23, 26, 30, 37]).

In [13], based on the 2-tuple linguistic model, the AHP numerical scale is developed, which is defined as below:

Definition 5 [13]: Let $\overline{S^{\mathrm{AHP}}}$ be the 2-tuple linguistic term set corresponding to $S^{\mathrm{AHP}}$ (i.e., $\overline{S^{\mathrm{AHP}}}=\{(s, \alpha)$ $\left.\left.\mid s \in S^{\mathrm{AHP}}, \alpha \in[-0.5,0.5)\right\}\right)$. The function $N S^{\mathrm{AHP}}$ : $\overline{S^{\mathrm{AHP}}} \rightarrow R^{+}$is called an AHP numerical scale function, which satisfies: (1) $N S^{\mathrm{AHP}}(s) \times N S^{\mathrm{AHP}}(\operatorname{Neg}(s))=1$, for any $s \in \overline{S^{\mathrm{AHP}}}$, and (2) $N S^{\mathrm{AHP}}\left(s_{i}\right)<N S^{\mathrm{AHP}}\left(s_{j}\right)$ if $i<j$.

Based on the AHP numerical scale function, we can transform an LPCM $L=\left(l_{i j}\right)_{n \times n}$ into a NPCM $A=\left(a_{i j}\right)_{n \times n}$, where $a_{i j}=N S^{\mathrm{AHP}}\left(l_{i j}\right)$ for $i, j=1,2, \ldots, n$. 


\section{The framework of the AHP with PIS}

By taking into account an un-negligible factor, PIS, in the AHP, this section proposes a novel AHP framework: the AHP framework with PIS.

As introduced in Section 2, in the traditional AHP, a decision maker provides LPCMs in the established hierarchical structure. Then, for conducting computation operation, LPCMs are transformed into NPCMs using a certain numerical scale function. The choice of numerical scale has an important influence on the final decision results, and there are several common numerical scale functions (e.g., [21, 26, 29, 30, 37, 38]). When selecting a numerical scale function to quantify the LPCMs (i.e., the transformation between linguistic information and numerical information), the PIS is an un-negligible factor and it has an important influence on the final decision results. Huizingh and Vrolijk [25], and Poyhonen et al. [35] have demonstrated the existence of PIS in the AHP. Recently, Li et al. [27] researched the PIS in linguistic decision making. Motivated by the challenge of modelling the PIS in AHP, and inspired by the works of Saaty [38], Huizingh and Vrolijk [25], Poyhonen [35], and Li et al. [27], we propose a novel AHP framework: AHP framework with the PIS. The proposed framework is described in Fig. 2.

There are two differences between AHP with the PIS and the AHP with the fixed numerical scale (FNS):

(1) consistency test. In the traditional AHP with a fixed numerical scale, the consistency test is conducted on NPCMs, and in the AHP with the PIS, it is to check the

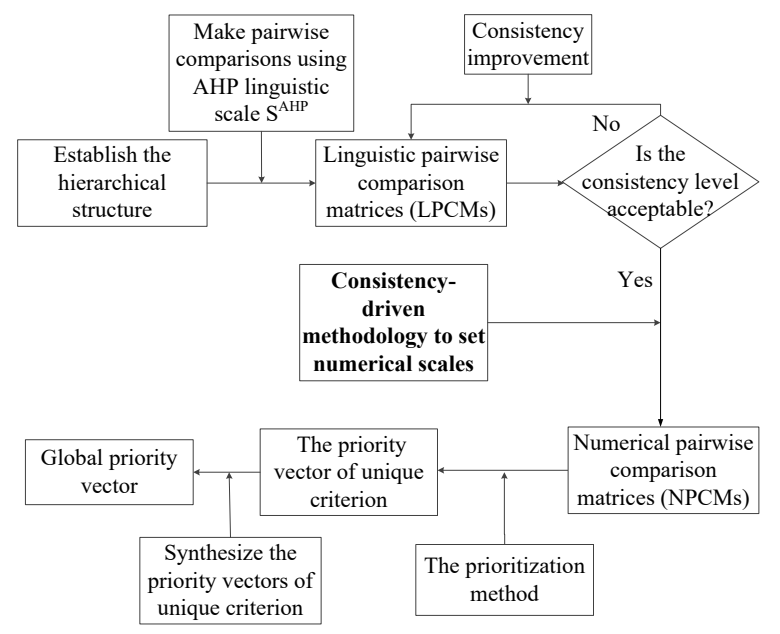

Fig. 2. The framework of AHP with the PIS. consistency of LPCMs; (2) the transformation process between LPCMs and NPCMs. In the AHP with the FNS, the transformation process is based on a certain numerical scale (e.g., the Saaty scale). In the AHP with the PIS, the transformation between LPCMs and NPCMs is conducted by the individual numerical scales.

(1) Consistency test regarding LPCMs

Up to now, a lot of works regarding the consistency issue of LPCMs have been reported (see [1], [44], [47] and [48]). In particular, transitive properties have been utilized to capture the consistency issues of LPCMs. Let $L=\left(l_{i j}\right)_{n \times n}$ be as above. In the following, we introduce several transitive properties of $L=\left(l_{i j}\right)_{n \times n}$ (see [18]):

a) Intransitivity. $l_{i j} \geq s_{g / 2}, \quad l_{j t} \geq s_{g / 2} \Rightarrow l_{i t}<s_{g / 2}$ for $\forall i, j, t$.

Example 1. Let $L=\left(l_{i j}\right)_{3 \times 3}$ be an LPCM over alternatives $\left\{x_{1}, x_{2}, x_{3}\right\}$, and $L$ is listed below.

$$
L=\left(\begin{array}{ccc}
s_{8} & s_{10} & s_{5} \\
s_{6} & s_{8} & s_{13} \\
s_{11} & s_{3} & s_{8}
\end{array}\right)
$$

In an LPCM $L, x_{1}$ is moderately more important than $x_{2}$, i.e., $l_{12}=s_{10}>s_{8}$, and $x_{2}$ is strongly plus more important than $x_{3}$, i.e., $l_{23}=s_{13}$ $>s_{8}$, while $x_{1}$ is strongly plus less important than $x_{3}$, i.e., $l_{13}=s_{5}<s_{8}$. Thus, $L$ is an LPCM with intransitivity.

b) Weak stochastic transitivity. $l_{i j} \geq s_{g / 2}$, $l_{j t} \geq s_{g / 2}, \Rightarrow l_{i t} \geq s_{g / 2}$ for $\forall i, j, t$.

Example 2. Let $L=\left(l_{i j}\right)_{3 \times 3}$ be an LPCM over alternatives $\left\{x_{1}, x_{2}, x_{3}\right\}$, and $L$ is listed below.

$$
L=\left(\begin{array}{ccc}
s_{8} & s_{10} & s_{11} \\
s_{6} & s_{8} & s_{13} \\
s_{5} & s_{3} & s_{8}
\end{array}\right)
$$

In an LPCM $L, x_{1}$ is moderately more important than $x_{2}$, i.e., $l_{12}=s_{10}>s_{8}, x_{2}$ is strongly plus more important than $x_{3}, l_{23}=s_{13}>s_{8}$, and $x_{1}$ is moderately plus more important than $x_{3}, l_{13}=s_{11}>s_{8}$. Thus, $L$ is an LPCM with weak stochastic transitivity.

c) Strong stochastic transitivity. $l_{i j} \geq s_{g / 2}$, $l_{j t} \geq s_{g / 2} \Rightarrow l_{i t} \geq \max \left(l_{i j}, l_{j t}\right)$ for $\forall i, j, t$.

Example 3. Let $L=\left(l_{i j}\right)_{3 \times 3}$ be an LPCM over alternatives $\left\{x_{1}, x_{2}, x_{3}\right\}$, and $L$ is listed below. 


$$
L=\left(\begin{array}{lll}
s_{8} & S_{10} & s_{14} \\
s_{6} & s_{8} & s_{13} \\
s_{11} & s_{3} & s_{8}
\end{array}\right)
$$

In an LPCM $L, x_{1}$ is moderately more important than $x_{2}$, i.e., $l_{12}=s_{10}>s_{8}, x_{2}$ is strongly plus more important than $x_{3}$, i.e., $l_{23}=s_{13}>s_{8}$, and $x_{1}$ is demonstrately more important than $x_{3}$, i.e., $l_{13}=s_{14}>\max \left\{s_{10}, s_{13}\right\}$. Thus, $L$ is an LPCM with strong stochastic transitivity.

d) Additive transitivity. $\Delta^{-1}\left(l_{i j}\right)+\Delta^{-1}\left(l_{j t}\right)-\frac{g}{2}$ $=\Delta^{-1}\left(l_{i t}\right)$ for $\forall i, j, t$.

Example 4. Let $L=\left(l_{i j}\right)_{3 \times 3}$ be an LPCM over alternatives $\left\{x_{1}, x_{2}, x_{3}\right\}$, and $L$ is listed below.

$$
L=\left(\begin{array}{lll}
s_{8} & s_{10} & s_{15} \\
s_{6} & s_{8} & s_{13} \\
s_{11} & s_{3} & s_{8}
\end{array}\right)
$$

In an LPCM $L, x_{1}$ is moderately more important than $x_{2}$, i.e., $l_{12}=s_{10}>s_{8}, x_{2}$ is strongly plus more important than $x_{3}$, i.e., $l_{23}=s_{13}>s_{8}$, and $x_{1}$ is very very strongly important than $x_{3}$, i.e., $l_{13}=s_{15}=\Delta^{-1}\left(s_{10}\right)+\Delta^{-1}\left(s_{13}\right)-s_{8}$. Thus, $L$ is an LPCM with additive transitivity.

Obviously, the condition of the additive transitivity is the most restrictive, and followed by the strong stochastic transitivity and the weak stochastic transitivity. Usually, if a set of pre-established transitive properties are satisfied, we then consider that the consistency level of an LPCM is acceptable. In this paper, we assume that the consistency level of an LPCM is acceptable when the weak stochastic transitivity is satisfied. To improve the consistency level of an LPCM, several approaches have been suggested (e.g., $[4,5$, 47]).

(2) Consistency-driven approach to obtain the numerical scale with PIS

In the AHP, the LPCMs given by a decision maker are often transformed into NPCMs for implementing the computation operation. Clearly, both the LPCMs and NPCMs are the preferences associated with the same decision maker. Naturally, if the consistency level of LPCMs is acceptable, then the consistency level of the transformed NPCMs should be as better as possible. Following this idea, we put forward a consistency-driven approach to set numerical scale with PIS. In the consistency-driven approach, a two-stage based optimization model is established to generate the individual numerical scales. The first-stage optimization model is to minimize the overall inconsistency level of NPCMs that transformed from LPCMs, and the second-stage optimization model is to obtain the unique optimal solution by further optimizing the optimal solution(s) obtained from the first-stage model.

The consistency-driven approach is formally presented in Section 4.

Discussion. Clearly, the consistency-driven approach is a two-procedure based approach. In the work of Dong et al. [13], a two-procedure based approach is also reported to set numerical scales in the AHP. In the following, the differences between our proposal and the work of Dong et al. [13] are analyzed:

(1) The first procedure is the detection of the individual characteristics in Dong et al. [13], and the first procedure of our proposal is the consistency test of LPCMs.

(2) In the second procedure of Dong et al. [13], a nonlinear programming model is constructed to yield individual numerical scales by optimally matching the individual characteristics generated from the first procedure. In the second procedure of our proposal, a consistency-driven optimization model that minimizes the inconsistency index of the transformed NPCMs is built to produce the individual numerical scales. In addition, the consistency-driven optimization model is converted into a linear programming model that can be easily solved.

\section{Consistency-driven methodology to deal with the PIS}

This section presents a consistency-driven approach to address the PIS in AHP. Specifically, we propose a consistency-driven optimization model to yield the individual numerical scales in section 4.1. Moreover, we make some discussions regarding the optimal solution(s) derived from the consistency-driven optimization model.

\subsection{Consistency-driven optimization model}

Recall that $L_{k}^{z}=\left(l_{i j}^{k, z}\right)_{n_{k}^{z} \times n_{k}^{z}} \quad\left(i, j=1, \ldots, n_{k}^{z}\right.$, $\left.z=1, \ldots, n_{k}, \quad k=1, \ldots, m-1\right)$ are the LPCMs in the established hierarchical structure. In the consistency-driven methodology, the LPCMs $L_{k}^{z}=\left(l_{i j}^{k, z}\right)_{n_{k}^{2} \times n_{k}^{z}}, \quad\left(z=1, \ldots, n_{k}, \quad k=1, \ldots, m-1\right) \quad$ are 
assumed to be consistent. There are several approaches (e.g., $[4,5])$ to improve the consistency level of the LPCM. Let $A_{k}^{z}=\left(a_{i j}^{k, z}\right)_{n_{i}^{z} \times n_{i}^{z}}$ be the NPCM associated with LPCM $L_{k}^{z}=\left(l_{i j}^{k, z}\right)_{n_{k}^{z} \times n_{k}^{z}}$. We know that both $L_{k}^{z}$ and $A_{k}^{z} \quad\left(z=1, \ldots, n_{k}, \quad k=1, \ldots, m-1\right) \quad$ are the preferences associated with the same decision maker. Naturally, we hope that the consistency level of $A_{k}^{z}$ should be as better as possible, due to the fact that the $\mathrm{LPCM} \quad L_{k}^{z} \quad\left(z=1, \ldots, n_{k}, \quad k=1, \ldots, m-1\right) \quad$ is $\quad$ of acceptable consistency.

Before proposing the consistency-driven optimization model, the consistency index ( $C I)$ of a NPCM is introduced.

For a NPCM $A=\left(a_{i j}\right)_{n \times n}$, if $a_{i t} \times a_{t j}=a_{i j}$ for $\forall i, j, t \in\{1,2, \ldots, n\}$, then $A$ is a completely consistent NPCM. In this case, $\log \left(a_{i t}\right)+\log \left(a_{t j}\right)=\log \left(a_{t j}\right)$, $\forall i, j, t \in\{1,2, \ldots, n\}$. Further, we have $\sum_{i, j, t=1, i<t<j}^{n}$ $\left|\log \left(a_{i t}\right)+\log \left(a_{t j}\right)-\log \left(a_{t j}\right)\right|=0$, if $A$ is a completely consistent NPCM. However, in practice, it is difficult to provide a completely consistent NPCM for a decision maker. So, consistency measures are often used. In the following, the consistency level of a NPCM is defined.

Definition 6: The consistency level of NPCM $A=\left(a_{i j}\right)_{n \times n}$ can be defined as follows:

$C L(A)=\frac{1}{n(n-1)(n-2)} \sum_{i, j, t=1, i<t<j}^{n}\left|\log \left(a_{i t}\right)+\log \left(a_{t j}\right)-\log \left(a_{i j}\right)\right|$.

Clearly, $C L(A) \in[0,1]$. The smaller the $C L(A)$ value, the better the consistency level of $A$ is.

Naturally, we hope that the transformed NPCMs $A_{k}^{z}\left(z=1, \ldots, n_{k}, \quad k=1, \ldots, m-1\right)$ are as consistent as possible, i.e.,

$$
\min \sum_{k=1}^{m-1} \sum_{z=1}^{n_{k}} C I\left(A_{k}^{z}\right)
$$

Meanwhile, the AHP numerical scale $N S^{\mathrm{AHP}}$ should satisfy the following two conditions (described as (8) and (9)):

$$
N S^{\mathrm{AHP}}\left(s_{i}\right) \leq N S^{\mathrm{AHP}}\left(s_{i+1}\right), i=9,10, \ldots, 16,
$$

and

$$
N S^{\mathrm{AHP}}\left(s_{i}\right) \times N S^{\mathrm{AHP}}\left(s_{16-i}\right)=1, i=9,10, \ldots, 16 .
$$

If we set $N S^{\mathrm{AHP}}\left(s_{i}\right)=\left\{\begin{array}{l}\frac{1}{9-i}, i=0,1,2, \ldots 7 \\ i-7, i=8,9, \ldots 16\end{array}\right.$, then it is the Saaty scale. To make a linkage with the Saaty scale, we adopt the following way to set the range of the individual numerical scales:

$$
i-7-\Delta \leq N S^{\mathrm{AHP}}\left(s_{i}\right) \leq i-7+\Delta, i=9,10, \ldots, 16
$$

where, $\Delta \in[0,1]$ is a parameter. Clearly, if we set $\Delta=0$, then $N S^{\mathrm{AHP}}$ is the Saaty scale.

Take logarithms on both sides, (8)-(10) can be equivalently written as (11)-(13), respectively:

$$
\begin{aligned}
& \log \left(N S^{\mathrm{AHP}}\left(s_{i}\right)\right) \leq \log \left(N S^{\mathrm{AHP}}\left(s_{i+1}\right)\right), i=9,10, \ldots, 16 \\
& \log \left(N S^{\mathrm{AHP}}\left(s_{i}\right)\right)+\log \left(N S^{\mathrm{AHP}}\left(s_{16-i}\right)\right)=0, \\
& i=9,10, \ldots, 16 \\
& \log (i-7-\Delta) \leq \log \left(N S^{\mathrm{AHP}}\left(s_{i}\right)\right) \leq \log (i-7+\Delta), \\
& i=9,10, \ldots, 16
\end{aligned}
$$

According to (7) and (11)-(13), we propose a consistency-driven optimization model:

$$
\begin{aligned}
& \min \sum_{k=1}^{m-1} \sum_{z=1}^{n_{k}} C I\left(A_{k}^{z}\right) \\
& =\sum_{k=1}^{m-1} \sum_{z=1}^{n_{k}} \frac{1}{n_{k}^{z}\left(n_{k}^{z}-1\right)\left(n_{k}^{z}-2\right)} \sum_{i, t, j=1, i<t<j}^{n_{k}^{z}}\left|\log \left(a_{i t}^{k, z}\right)+\log \left(a_{i j}^{k, z}\right)-\log \left(a_{i j}^{k, z}\right)\right| \\
& \text { s.t. } \\
& \qquad \begin{array}{l}
a_{i j}^{k, z}=N S^{\mathrm{AHP}}\left(l_{i j}^{k, z}\right), i, j=1, \ldots n_{k}^{z}, z=1, \ldots, n_{k}, k=1, \ldots, m-1 \\
\log \left(N S^{\mathrm{AHP}}\left(s_{i}\right)\right) \leq \log \left(N S^{\mathrm{AHP}}\left(s_{i+1}\right)\right), i=9,10, \ldots, 16 \\
\log \left(N S^{\mathrm{AHP}}\left(s_{i}\right)\right)+\log \left(N S^{\mathrm{AHP}}\left(s_{16-i}\right)\right)=0, i=9,10, \ldots, 16 \\
\log (i-7-\Delta) \leq \log \left(N S^{\mathrm{AHP}}\left(s_{i}\right)\right) \leq \log (i-7+\Delta), i=9,10, \ldots, 16
\end{array}
\end{aligned}
$$

In model $(14), N S^{\mathrm{AHP}}\left(s_{i}\right)(i=0,1, \ldots, 16)$ are decision variables. Solving model (14) yields the AHP numerical scale $N S^{\mathrm{AHP}}\left(s_{i}\right)(i=0,1, \ldots, 16)$. Based on the obtained $N S^{\mathrm{AHP}}\left(s_{i}\right) \quad(i=0,1, \ldots, 16)$, LPCMs can be transformed into NPCMs.

For convenience, let $p(s)\left(s \in S^{\mathrm{AHP}}\right)$ be the position index of $\boldsymbol{s}$. For instance, we have $p\left(s_{i}\right)=i$. Let $B^{i}=\log \left(N S^{\mathrm{AHP}}\left(s_{i}\right)\right)$, then model (14) can be written as the following model: 


$$
\begin{aligned}
& \min \sum_{k=1}^{m-1} \sum_{z=1}^{n_{k}} \frac{1}{n_{k}^{z}\left(n_{k}^{z}-1\right)\left(n_{k}^{z}-2\right)} \sum_{i, t, j=1, i<<j}^{n_{k}^{z}}\left|B^{p\left(l_{l i t}^{k, z}\right)}+B^{p\left(l_{i}^{k, z}\right)}-B^{p\left(l_{l}^{k, z}\right)}\right| \\
& \text { s.t. } \\
& \qquad \begin{array}{l}
B^{p\left(l_{i}^{k, z}\right)}=\log \left(N S^{A H P}\left(s_{p\left(l_{i j}^{k, z}\right)}\right)\right), i, j=1, \ldots n_{k}^{z}, z=1, \ldots, n_{k}, k=1, \ldots, m-1 \\
B^{i}-B^{i+1} \leq 0, i=9,10, \ldots, 16 \\
B^{i}+B^{16-i}=0, i=9,10, \ldots, 16 \\
\log (i-7-\Delta) \leq B^{i} \leq \log (i-7+\Delta), i=9,10, \ldots, 16
\end{array}
\end{aligned}
$$

where $B^{i}(i=0,1,2, \ldots, 16)$ are decision variables.

In the following, we propose a method to transform model (15) into a linear programming model, which is described as Theorem 1 .

For simplicity, we set $K=\{1, \ldots, m-1\}$, $N^{k}=\left\{1, \ldots, n_{k}\right\} \quad(k \in K), \quad$ and $Q_{k}^{z}=\left\{1, \ldots, n_{k}^{z} \times\right.$ $\left.\left(n_{k}^{z}-1\right) \times\left(n_{k}^{z}-2\right) / 6\right\}, \quad z \in N_{k}, k \in K$.

Theorem 1. Let $M_{q_{k}^{z}}$ be a variable, where $\left|\log \left(a_{i t}^{k, z}\right)+\log \left(a_{t j}^{k, z}\right)-\log \left(a_{i j}^{k, z}\right)\right| \leq M_{q_{k}^{z}} \quad\left(\quad q_{k}^{z} \in Q_{k}^{z} \quad\right.$, $z \in N_{k}, k \in K$ ). Model (15) can be equivalently transformed into the following linear programming model.

$$
\begin{aligned}
& \min \sum_{k=1}^{m-1} \sum_{z=1}^{n_{k}} \frac{1}{n_{k}^{z}\left(n_{k}^{z}-1\right)\left(n_{k}^{z}-2\right)} \sum_{q_{k}^{z}=1}^{n_{k}^{z} \times\left(n_{k}^{z}-1\right) \times\left(n_{k}^{z}-2\right) / 6} M_{q_{k}^{z}} \\
& \text { s.t. }
\end{aligned}
$$

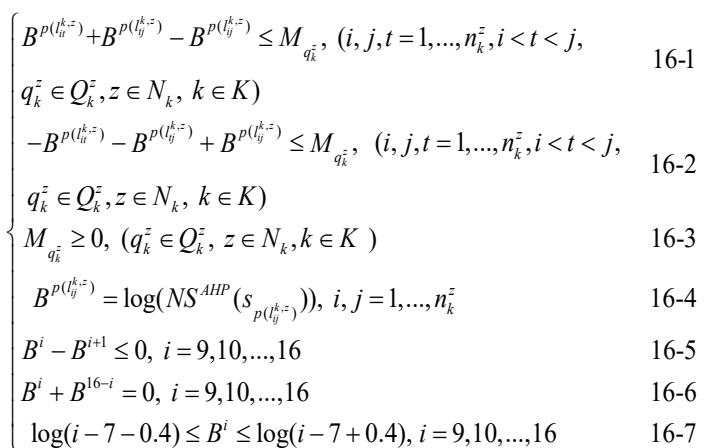

Proof. In model (16), constrains (16-1), (16-2), and (16-3) guarantee that $M_{q_{k}^{z}} \geq \mid \log \left(a_{i t}^{k, z}\right)+\log \left(a_{t j}^{k, z}\right)$ $-\log \left(a_{i j}^{k, z}\right) \mid$. Moreover, any feasible solution that satisfies $M_{q_{k}^{z}}>\left|\log \left(a_{i t}^{k, z}\right)+\log \left(a_{i j}^{k, z}\right)-\log \left(a_{i j}^{k, z}\right)\right|$ is not the optimal solution, based on the objective function of model (16). So, constrains (16-1), (16-2), and (16-3) ensure that $M_{q_{k}^{z}}=\left|\log \left(a_{i t}^{k, z}\right)+\log \left(a_{i j}^{k, z}\right)-\log \left(a_{i j}^{k, z}\right)\right|$. Therefore, model (15) can be transformed into (16). This completes the proof of Theorem 1 .

\subsection{Further discussion}

This section discusses the problem of uniqueness of optimal solution to model (14).

In Section 4.1, we can obtain the optimal solution(s) to model (14). Nevertheless, in some cases, the optimal solution(s) to model (14) may not be unique. In particular, some of them are unreasonable (in the sense of consistency). To demonstrate this issue, Example 5 is provided.

Example 5. Suppose that there is a hierarchical structure (see Fig. 3), which consists of one goal $\{G\}$, three criteria $\left\{C_{1}, C_{2}, C_{3}\right\}$, and three alternatives $X=\left\{x_{1}, x_{2}, x_{3}\right\}$. The LPCMs given by a decision maker based on $S^{\mathrm{AHP}}$ are listed as follows,

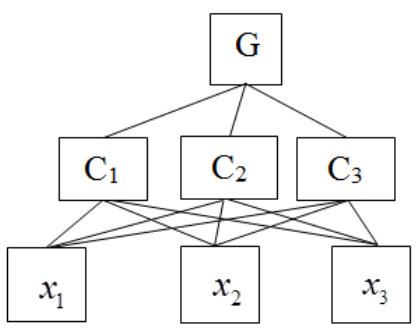

Fig. 3. The hierarchical structure in Example 5.

Table 3. The individual numerical scales in $\Omega_{1}$ and $\Omega_{2}$

\begin{tabular}{l|ccccccccc}
\hline & $\mathbf{8}$ & $\mathbf{9}$ & $\mathbf{1 0}$ & $\mathbf{1 1}$ & $\mathbf{1 2}$ & $\mathbf{1 3}$ & $\mathbf{1 4}$ & $\mathbf{1 5}$ & $\mathbf{1 6}$ \\
\hline$\Omega_{1}: N S^{\mathrm{AHP}}\left(s_{i}\right)$ & 1 & 2.29 & 2.29 & 3.57 & 4.38 & 5 & 7.28 & 7.28 & 9.19 \\
$\Omega_{2}: N S^{\mathrm{AHP}}\left(s_{i}\right)$ & 1 & 2 & 2 & 3.60 & 4.51 & 5 & 7.03 & 7.03 & 9.6 \\
\hline
\end{tabular}




$$
\begin{aligned}
L_{1}^{1}=\left(\begin{array}{lll}
s_{8} & s_{4} & s_{10} \\
s_{12} & s_{8} & s_{14} \\
s_{6} & s_{2} & s_{8}
\end{array}\right) & L_{2}^{1}=\left(\begin{array}{ccc}
s_{8} & s_{7} & s_{8} \\
s_{9} & s_{8} & s_{10} \\
s_{8} & s_{6} & s_{8}
\end{array}\right) \\
L_{2}^{1}=\left(\begin{array}{lll}
s_{8} & s_{7} & s_{16} \\
s_{9} & s_{8} & s_{16} \\
s_{0} & s_{0} & s_{8}
\end{array}\right) & L_{2}^{2}=\left(\begin{array}{lll}
s_{8} & s_{9} & s_{6} \\
s_{7} & s_{8} & s_{1} \\
s_{10} & s_{15} & s_{8}
\end{array}\right)
\end{aligned}
$$

In this example, we set $\Delta=0.4$. Using model (14), we can obtain a set of optimal solutions. Here, we only list two optimal solutions: $\Omega_{1}$ : $\left\{N S^{\mathrm{AHP}(1)}\left(s_{i}\right), i=0,1, \ldots, 16\right\} \quad$ and $\quad \Omega_{2}: \quad\left\{\mathrm{NS}^{\mathrm{AHP}(2)}\left(s_{i}\right)\right.$, $i=0,1, \ldots, 16\}$, and they are provided in Table 3 .

Based on $\Omega_{1}$ and $\Omega_{2}, L_{1}^{1}, L_{2}^{1}, L_{2}^{2}$ and $L_{2}^{3}$ can be transformed into NPCMs $A_{1}^{1}, A_{2}^{1}, A_{2}^{2}$ and $A_{2}^{3}$, and they are listed below:

(1) the NPCMs $A_{k}^{z^{(1)}}\left(k=1,2, z=1, \ldots, n_{k}\right)$ under $\Omega_{1}$

$$
\begin{array}{ll}
A_{1}^{1^{(1)}}=\left(\begin{array}{ccc}
1 & 0.23 & 2.29 \\
4.38 & 1 & 7.28 \\
0.44 & 0.14 & 1
\end{array}\right), & A_{2}^{(1)}=\left(\begin{array}{ccc}
1 & 0.44 & 1 \\
2.29 & 1 & 2.29 \\
1 & 0.44 & 1
\end{array}\right), \\
A_{2}^{2^{(1)}}=\left(\begin{array}{ccc}
1 & 2.29 & 0.44 \\
0.44 & 1 & 0.14 \\
2.29 & 7.28 & 1
\end{array}\right), & A_{2}^{3^{(1)}}=\left(\begin{array}{ccc}
1 & 0.44 & 9.19 \\
2.29 & 1 & 9.19 \\
0.11 & 0.11 & 1
\end{array}\right) .
\end{array}
$$

(2) the NPCMs $A_{k}^{z^{(2)}}\left(z=1, \ldots, n_{k}, k=1,2\right)$ under $\Omega_{2}$

$$
\begin{array}{rlr}
A_{1}^{(2)} & =\left(\begin{array}{ccc}
1 & 0.22 & 2 \\
4.51 & 1 & 7.03 \\
0.5 & 0.14 & 1
\end{array}\right), & A_{2}^{1^{(2)}}=\left(\begin{array}{ccc}
1 & 0.5 & 1 \\
2 & 1 & 2 \\
1 & 0.5 & 1
\end{array}\right), \\
A_{2}^{2^{(2)}}=\left(\begin{array}{ccc}
1 & 2 & 0.5 \\
0.5 & 1 & 0.14 \\
2 & 7.03 & 1
\end{array}\right), & A_{2}^{3^{(2)}}=\left(\begin{array}{ccc}
1 & 0.5 & 9.6 \\
2 & 1 & 9.6 \\
0.1 & 0.1 & 1
\end{array}\right) .
\end{array}
$$

According to definition 6 , we can obtain the consistency levels of the transformed NPCMs $A_{k}^{z^{(1)}}$ and $A_{k}^{z^{(2)}}\left(z=1, \ldots, n_{k}, k=1,2\right)$ under $\Omega_{1}$ and $\Omega_{2}$, respectively, which are listed in Table 4.

Table 4. The consistency levels of NPCMs under $\Omega_{1}$ and $\Omega_{2}$, respectively

\begin{tabular}{ccccc}
\hline & $C I\left(A_{2}^{1}\right)$ & $C I\left(A_{2}^{1}\right)$ & $C I\left(A_{2}^{2}\right)$ & $C I\left(A_{2}^{3}\right)$ \\
\hline$\Omega_{1}$ & 0.08 & 0 & 0.05 & $\mathbf{0 . 1 4}$ \\
\hline$\Omega_{2}$ & 0.06 & 0 & 0.09 & $\mathbf{0 . 1 2}$ \\
\hline
\end{tabular}

Example 5 shows that: (1) the optimal solutions to model (14) are not unique; and $\max _{k, z}\left\{C I\left(A_{k}^{z(1)}\right)\right\} \geq \max _{k, z}\left\{C I\left(A_{k}^{z(2)}\right)\right\}$, this implies that the optimal solution $\Omega_{2}$ is better than $\Omega_{1}$, in the sense of consistency. Therefore, to further optimize the optimal solutions to model (14) is necessary.

Let $M^{*}$ be the optimal objective value to model (14), let $\Omega=\left\{\Omega_{1}, \Omega_{2}, \ldots, \Omega_{n}\right\} \quad\left(\Omega_{r}=\left\{N S^{\operatorname{AHP}(r)}\left(s_{0}\right), \ldots\right.\right.$, $\left.\left.N S^{\mathrm{AHP}(r)}\left(s_{16}\right)\right\}, r=1,2, \ldots, n\right)$ be a set of optimal solutions to model (14), let $A_{k}^{z^{(r)}}\left(z=1,2, \ldots, n_{k}\right.$, $k=1,2, . ., m-1)$ be the transformed NPCMs under the optimal solution $\Omega_{r}(r=1,2, \ldots, n)$. Then, using the optimization model

$$
\min _{\Omega_{r} \in \Omega} \max _{k \in K, z \in N_{k}}\left\{C I\left(A_{k}^{z(r)}\right)\right\}
$$

generates the unique optimal solution. Model (17) further minimizes the maximal consistency index of the transformed NPCMs.

Further, model (17) can be rewritten as follows:

$$
\begin{aligned}
& \min \max _{k \in K, z \in N_{k}}\left\{C I\left(A_{k}^{z}\right)\right\} \\
& =\min \max _{k \in K, z \in N_{k}}\left\{\frac{1}{n_{k}^{z}\left(n_{k}^{z}-1\right)\left(n_{k}^{z}-2\right)} \sum_{i, j, t=1, i<<j}^{n_{*}^{k}}\left|\log \left(a_{i t}^{k, z}\right)+\log \left(a_{t j}^{k, z}\right)-\log \left(a_{i j}^{k, z}\right)\right|\right\} \\
& \text { s.t. } \\
& \left\{\begin{array}{lr}
a_{i j}^{k, z}=N S^{\mathrm{AHP}}\left(l_{i j}^{k, z}\right), i, j=1, \ldots, n_{k}^{z}, z=1, \ldots, n_{k}, k=1, \ldots, m-1 & 18-1 \\
\sum_{k=1}^{m-1} \sum_{z=1}^{n_{k}} \frac{1}{n_{k}^{z}\left(n_{k}^{z}-1\right)\left(n_{k}^{z}-2\right)} \sum_{i, j, t=1, i<<j}^{n_{k}^{k}}\left|\log \left(a_{i t}^{k, z}\right)+\log \left(a_{i j}^{k, z}\right)-\log \left(a_{i j}^{k, z}\right)\right|=M^{*} & 18-2 \\
\log \left(N S^{\mathrm{AHP}}\left(s_{i}\right)\right) \leq \log \left(N S^{\mathrm{AHP}}\left(s_{i+1}\right)\right), i=9,10, \ldots, 16 & 18-3 \\
\log \left(N S^{\mathrm{AHP}}\left(s_{i}\right)\right)+\log \left(N S^{\mathrm{AHP}}\left(s_{16-i}\right)\right)=0, i=9,10, \ldots, 16 & 18-4 \\
\log (i-7-\Delta) \leq \log \left(N S^{\mathrm{AHP}}\left(s_{i}\right)\right) \leq \log (i-7+\Delta), i=9,10, \ldots, 16
\end{array}\right.
\end{aligned}
$$

In model $(18), \quad N S^{\mathrm{AHP}}\left(s_{i}\right) \quad(i=0, \ldots, 16)$ are decision variables. The constraints (18-1)-(18-5) guarantee that the optimal solutions of model (18) are subsets of the feasible solution of model (14), constraints (18-3), (18-4) guarantee that the AHP numerical scale $N S^{\mathrm{AHP}}\left(S_{i}\right) \quad(i=0, \ldots, 16)$ is ordered and reciprocal, constraint (18-5) is used to control the range of individual numerical scales.

Solving model (18) obtains the optimal individual numerical scales. Let $p(s) \quad\left(s \in S^{\mathrm{AHP}}\right)$ and $B^{i}$ $(i=0,1, \ldots, 16)$ be as above. Model (18) can be equally written as model (19). 


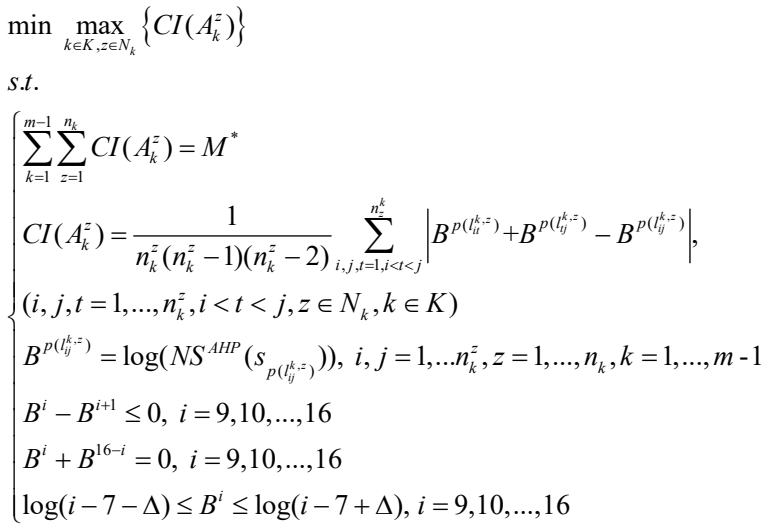

In model (19), $\quad B^{i}(i=0,1,2, \ldots, 16)$ are the decision variables. Solving model (19) obtains the optimal solution $B^{i, *} \quad(i=0,1,2, \ldots, 16) \quad$ to $B^{i}(i=0,1,2, \ldots, 16)$. Further, we obtain the individual numerical scales by $N S^{A H P}\left(s_{i}\right)=e^{B^{i *}} \quad(i=0,1,2, \ldots, 16)$.

Model (19) is a non-linear programming model. To solve model (19) easily, Theorem 2 is proposed to transform model (19) into a linear programming model.

Theorem 2. Let $M_{q_{k}^{z}}$ and $\lambda$ be two variables, and they satisfy: $\left|\log \left(a_{i t}^{k, z}\right)+\log \left(a_{i j}^{k, z}\right)-\log \left(a_{i j}^{k, z}\right)\right| \leq M_{q_{k}^{z}}$ $\left(q_{k}^{z} \in Q_{k}^{z}, \quad z \in N_{k}, \quad k \in K\right)$. Then, model (19) can be equally converted into the linear programming model (20).

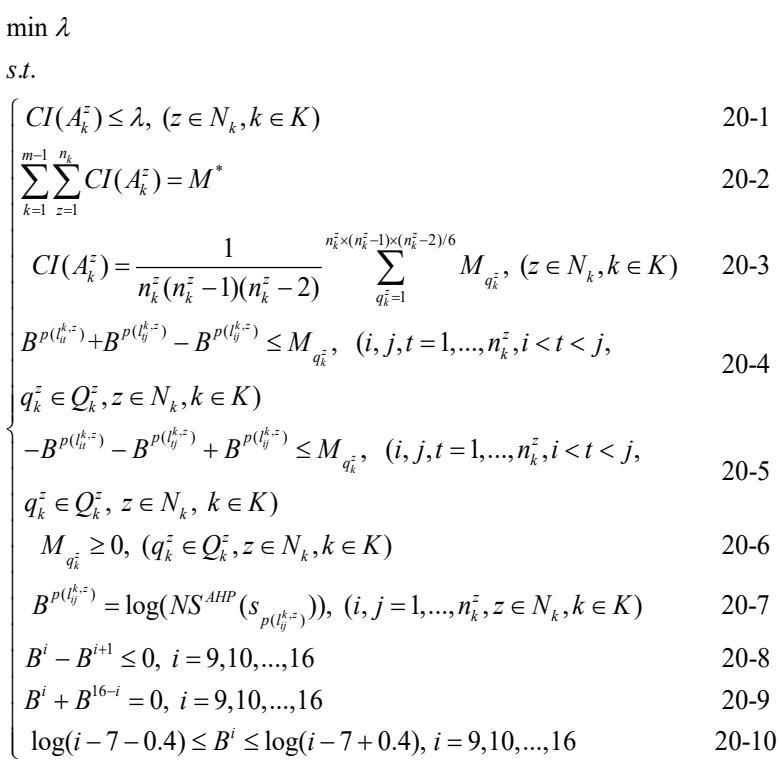
$\lambda \geq \max _{k \in K, z \in N_{k}}\left\{C I\left(A_{k}^{z}\right)\right\}$. Moreover, any feasible solutions with $\lambda>\max _{k \in K, z \in N_{k}}\left\{C I\left(A_{k}^{z}\right)\right\}$ are not the optimal solutions to model (20), according to its objective function. As a result, we have $\lambda=\max _{k \in K, z \in N_{k}}\left\{C I\left(A_{k}^{z}\right)\right\}$. Constraints

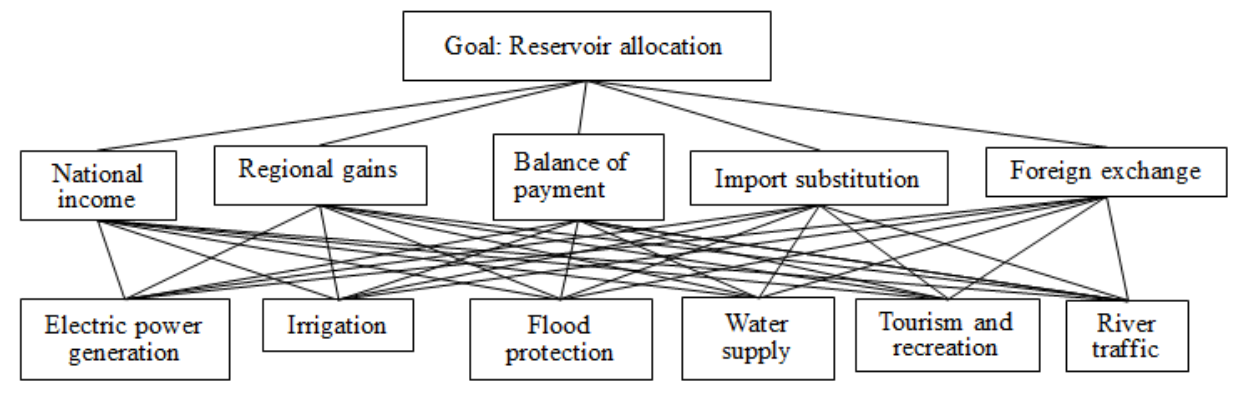

Fig. 4. Reservoir storage allocation.

Table 5. LPCM with respect to reservoir storage allocation $\left(L_{1}^{1}\right)$

\begin{tabular}{llllll}
\hline Goal & $\begin{array}{l}\text { National } \\
\text { income }\end{array}$ & Regional gains & $\begin{array}{l}\text { Balance of } \\
\text { payment }\end{array}$ & Import substitution & $\begin{array}{l}\text { Foreign } \\
\text { exchange }\end{array}$ \\
\hline National income & $S_{8}$ & $S_{9}$ & $S_{12}$ & $S_{10}$ & $S_{9}$ \\
Foreign exchange & $S_{7}$ & $S_{8}$ & $S_{14}$ & $S_{10}$ & $S_{10}$ \\
Balance of payment & $S_{4}$ & $S_{2}$ & $S_{8}$ & $S_{5}$ & $S_{4}$ \\
Import substitution & $S_{6}$ & $S_{6}$ & $S_{11}$ & $S_{8}$ & $S_{10}$ \\
Regional gains & $S_{7}$ & $S_{6}$ & $S_{12}$ & $S_{6}$ & $S_{8}$ \\
\hline
\end{tabular}


Table 6. LPCM with respect to national income $\left(L_{2}^{1}\right)$

\begin{tabular}{llllllc}
\hline National income & $\begin{array}{l}\text { Electric power } \\
\text { generation }\end{array}$ & Irrigation & $\begin{array}{l}\text { Flood } \\
\text { protection }\end{array}$ & $\begin{array}{l}\text { Water } \\
\text { supply }\end{array}$ & $\begin{array}{l}\text { Tourism } \\
\text { recreation }\end{array}$ & $\begin{array}{l}\text { River } \\
\text { traffic }\end{array}$ \\
\hline $\begin{array}{l}\text { Electric power } \\
\text { generation }\end{array}$ & $S_{8}$ & $S_{12}$ & $S_{10}$ & $S_{13}$ & $S_{14}$ & $S_{12}$ \\
Irrigation & $S_{4}$ & $S_{8}$ & $S_{2}$ & $S_{7}$ & $S_{9}$ & $S_{9}$ \\
Flood protection & $S_{6}$ & $S_{14}$ & $S_{8}$ & $S_{14}$ & $S_{10}$ & $S_{11}$ \\
Water supply & $S_{3}$ & $S_{9}$ & $S_{2}$ & $S_{8}$ & $S_{7}$ & $S_{8}$ \\
Tourism recreation & $S_{2}$ & $S_{7}$ & $S_{6}$ & $S_{9}$ & $S_{8}$ & $S_{9}$ \\
River traffic & $S_{4}$ & $S_{7}$ & $S_{5}$ & $S_{8}$ & $S_{7}$ & $S_{8}$ \\
\hline
\end{tabular}

Table 7. LPCM with respect to regional gains $\left(L_{2}^{2}\right)$

\begin{tabular}{llllllc}
\hline Regional gains & $\begin{array}{l}\text { Electric power } \\
\text { generation }\end{array}$ & Irrigation & $\begin{array}{l}\text { Flood } \\
\text { protection }\end{array}$ & $\begin{array}{l}\text { Water } \\
\text { supply }\end{array}$ & $\begin{array}{l}\text { Tourism } \\
\text { recreation }\end{array}$ & $\begin{array}{l}\text { River } \\
\text { traffic }\end{array}$ \\
\hline $\begin{array}{l}\text { Electric power } \\
\text { generation }\end{array}$ & $S_{8}$ & $S_{4}$ & $S_{6}$ & $S_{3}$ & $S_{6}$ & $S_{8}$ \\
Irrigation & $S_{12}$ & $S_{8}$ & $S_{9}$ & $S_{4}$ & $S_{9}$ & $S_{11}$ \\
Flood protection & $S_{10}$ & $S_{7}$ & $S_{8}$ & $S_{8}$ & $S_{9}$ & $S_{10}$ \\
Water supply & $S_{13}$ & $S_{12}$ & $S_{8}$ & $S_{8}$ & $S_{8}$ & $S_{14}$ \\
Tourism recreation & $S_{10}$ & $S_{7}$ & $S_{7}$ & $S_{8}$ & $S_{8}$ & $S_{12}$ \\
River traffic & $S_{8}$ & $S_{5}$ & $S_{6}$ & $S_{2}$ & $S_{4}$ & $S_{8}$ \\
\hline
\end{tabular}

Table 8. LPCM with respect to balance of payment $\left(L_{2}^{3}\right)$

\begin{tabular}{|c|c|c|c|c|c|c|}
\hline Balance of payment & $\begin{array}{l}\text { Electric power } \\
\text { generation }\end{array}$ & Irrigation & $\begin{array}{l}\text { Flood } \\
\text { protection }\end{array}$ & $\begin{array}{l}\text { Water } \\
\text { supply }\end{array}$ & $\begin{array}{l}\text { Tourism } \\
\text { recreation }\end{array}$ & $\begin{array}{l}\text { River } \\
\text { traffic }\end{array}$ \\
\hline Electric power generation & $s_{8}$ & $s_{10}$ & $S_{14}$ & $s_{13}$ & $s_{10}$ & $s_{11}$ \\
\hline Irrigation & $s_{6}$ & $s_{8}$ & $s_{12}$ & $s_{9}$ & $s_{10}$ & $S_{7}$ \\
\hline Flood protection & $s_{2}$ & $s_{4}$ & $S_{8}$ & $s_{5}$ & $s_{2}$ & $s_{6}$ \\
\hline Water supply & $s_{3}$ & $s_{7}$ & $s_{11}$ & $s_{8}$ & $s_{7}$ & $s_{9}$ \\
\hline Tourism recreation & $S_{6}$ & $s_{6}$ & $s_{14}$ & $S_{9}$ & $S_{8}$ & $S_{9}$ \\
\hline River traffic & $s_{5}$ & $s_{9}$ & $S_{10}$ & $s_{7}$ & $s_{7}$ & $S_{8}$ \\
\hline
\end{tabular}

Table 9. LPCM with respect to import substitution $\left(L_{2}^{4}\right)$

\begin{tabular}{|c|c|c|c|c|c|c|}
\hline Import substitution & $\begin{array}{l}\text { Electric power } \\
\text { generation }\end{array}$ & Irrigation & $\begin{array}{l}\begin{array}{l}\text { Flood } \\
\text { protection }\end{array} \\
\end{array}$ & $\begin{array}{l}\text { Water } \\
\text { supply }\end{array}$ & $\begin{array}{l}\text { Tourism } \\
\text { recreation }\end{array}$ & $\begin{array}{l}\text { River } \\
\text { traffic } \\
\end{array}$ \\
\hline $\begin{array}{l}\text { Electric power } \\
\text { generation }\end{array}$ & $S_{8}$ & $S_{10}$ & $S_{16}$ & $S_{14}$ & $s_{11}$ & $S_{10}$ \\
\hline Irrigation & $s_{6}$ & $s_{8}$ & $S_{10}$ & $s_{13}$ & $s_{9}$ & $s_{6}$ \\
\hline Flood protection & $s_{0}$ & $s_{6}$ & $S_{8}$ & $s_{7}$ & $S_{5}$ & $s_{4}$ \\
\hline Water supply & $S_{2}$ & $S_{3}$ & $s_{9}$ & $S_{8}$ & $s_{3}$ & $s_{3}$ \\
\hline Tourism recreation & $S_{5}$ & $s_{7}$ & $S_{11}$ & $s_{13}$ & $S_{8}$ & $S_{7}$ \\
\hline River traffic & $s_{6}$ & $s_{10}$ & $s_{12}$ & $s_{13}$ & $s_{9}$ & $s_{8}$ \\
\hline
\end{tabular}


Table 10. LPCM with respect to foreign exchange $\left(L_{2}^{5}\right)$

\begin{tabular}{lllllll}
\hline Foreign exchange & $\begin{array}{l}\text { Electric power } \\
\text { generation }\end{array}$ & Irrigation & $\begin{array}{l}\text { Flood } \\
\text { protection }\end{array}$ & $\begin{array}{l}\text { Water } \\
\text { supply }\end{array}$ & $\begin{array}{l}\text { Tourism } \\
\text { recreation }\end{array}$ & $\begin{array}{l}\text { River } \\
\text { traffic }\end{array}$ \\
\hline $\begin{array}{l}\text { Electric power } \\
\text { generation }\end{array}$ & $S_{8}$ & $S_{11}$ & $S_{13}$ & $S_{14}$ & $S_{9}$ & $S_{9}$ \\
Irrigation & $S_{5}$ & $S_{8}$ & $S_{9}$ & $S_{9}$ & $S_{8}$ & $S_{6}$ \\
Flood protection & $S_{3}$ & $S_{7}$ & $S_{8}$ & $S_{9}$ & $S_{3}$ & $S_{8}$ \\
Water supply & $S_{2}$ & $S_{7}$ & $S_{7}$ & $S_{8}$ & $S_{4}$ & $S_{2}$ \\
Tourism recreation & $S_{7}$ & $S_{8}$ & $S_{13}$ & $S_{12}$ & $S_{8}$ & $S_{8}$ \\
River traffic & $S_{7}$ & $S_{10}$ & $S_{8}$ & $S_{14}$ & $S_{8}$ & $S_{8}$ \\
\hline
\end{tabular}

Table 11. The individual numerical scales

\begin{tabular}{cccccccccc}
\hline$s_{i}$ & $S_{0}$ & $S_{1}$ & $S_{2}$ & $S_{3}$ & $S_{4}$ & $S_{5}$ & $S_{6}$ & $S_{7}$ & $S_{8}$ \\
$N S^{\mathrm{AHP}}\left(s_{i}\right)$ & 0.11 & 0.12 & 0.15 & 0.18 & 0.22 & 0.27 & 0.38 & 0.62 & 1 \\
\hline$S_{i}$ & $S_{9}$ & $S_{10}$ & $S_{11}$ & $S_{12}$ & $S_{13}$ & $S_{14}$ & $S_{15}$ & $S_{16}$ \\
$N S^{\mathrm{AHP}}\left(s_{i}\right)$ & 1.6 & 2.6 & 3.66 & 4.6 & 5.6 & 6.6 & 8.01 & 9.4 \\
\hline
\end{tabular}

$(20-4),(20-5),(20-6)$ and the objective function in model (20) guarantee that $\left|\log \left(a_{i t}^{k, z}\right)+\log \left(a_{i j}^{k, z}\right)-\log \left(a_{i j}^{k, z}\right)\right|=M_{q_{k}^{z}}$. Thus model (19) can be equally converted into model $(20)$.

\section{Practical example}

In this section, a practical example that presented in Srdjevic [41] is used to show the application process of our proposal.

This example focuses on the issue of reservoir water allocated to multiple purposes. The hierarchical structure that described as Fig. 4 is used by a decision maker to select profitable purpose. The hierarchical structure is made up of three levels: the goal level, the criterion level and the alternative level. The LPCMs expressed by the decision maker are provided in Tables 5-10.

Firstly, we use model (14) to obtain the optimal objective value $M^{*}$, and we further utilize model (20) to obtain the unique individual numerical scale of $S^{\mathrm{AHP}}$ , which are listed in Table 11.

Meanwhile, the LPCMs are transformed into NPCMs using the obtained numerical scales with the PIS. The transformed NPCMs are listed below:

$$
A_{1}^{1}=\left(\begin{array}{ccccc}
1 & 1.6 & 4.6 & 2.6 & 1.6 \\
0.62 & 1 & 6.6 & 2.6 & 2.6 \\
0.22 & 0.15 & 1 & 0.27 & 0.22 \\
0.38 & 0.38 & 3.66 & 1 & 2.6 \\
0.62 & 0.38 & 4.6 & 0.38 & 1
\end{array}\right),
$$$$
A_{2}^{1}=\left(\begin{array}{cccccc}
1 & 4.6 & 2.6 & 5.6 & 6.6 & 4.6 \\
0.22 & 1 & 0.15 & 0.62 & 1.6 & 1.6 \\
0.38 & 6.6 & 1 & 6.6 & 2.6 & 3.66 \\
0.18 & 1.6 & 0.15 & 1 & 0.62 & 1 \\
0.15 & 0.62 & 0.38 & 1.6 & 1 & 1.6 \\
0.22 & 0.62 & 0.27 & 1 & 0.62 & 1
\end{array}\right),
$$$$
A_{2}^{2}=\left(\begin{array}{cccccc}
1 & 0.22 & 0.38 & 0.18 & 0.38 & 1 \\
4.6 & 1 & 1.6 & 0.22 & 1.6 & 3.66 \\
2.6 & 0.62 & 1 & 1 & 1.6 & 2.6 \\
5.6 & 4.6 & 1 & 1 & 1 & 6.6 \\
2.6 & 0.62 & 0.62 & 1 & 1 & 4.6 \\
1 & 0.27 & 0.38 & 0.15 & 0.22 & 1
\end{array}\right) \text {, }
$$$$
A_{2}^{3}=\left(\begin{array}{cccccc}
1 & 2.6 & 6.6 & 5.6 & 0.62 & 3.66 \\
0.38 & 1 & 4.6 & 1.6 & 0.62 & 0.62 \\
0.15 & 0.22 & 1 & 0.27 & 0.15 & 0.38 \\
0.18 & 0.62 & 3.66 & 1 & 0.62 & 1.6 \\
0.38 & 0.38 & 6.6 & 1.6 & 1 & 1.6 \\
0.27 & 1.6 & 0.62 & 0.62 & 0.62 & 1
\end{array}\right),
$$ 


$$
\begin{aligned}
A_{2}^{4} & =\left(\begin{array}{cccccc}
1 & 2.6 & 9.4 & 6.6 & 3.66 & 2.6 \\
0.38 & 1 & 2.6 & 5.6 & 1.6 & 0.38 \\
0.11 & 0.38 & 1 & 0.62 & 0.27 & 0.22 \\
0.15 & 0.18 & 1.6 & 1 & 0.18 & 0.18 \\
0.27 & 0.62 & 3.66 & 5.6 & 1 & 0.62 \\
0.38 & 2.6 & 4.6 & 5.6 & 1.6 & 1
\end{array}\right), \\
A_{2}^{5} & =\left(\begin{array}{cccccc}
1 & 3.66 & 5.6 & 6.6 & 1.6 & 1.6 \\
0.27 & 1 & 1.6 & 1.6 & 1 & 0.38 \\
0.18 & 0.62 & 1 & 1.6 & 0.18 & 1 \\
0.15 & 0.62 & 0.62 & 1 & 0.22 & 0.15 \\
0.62 & 1 & 5.6 & 4.6 & 1 & 1 \\
0.62 & 2.6 & 1 & 6.6 & 1 & 1
\end{array}\right) .
\end{aligned}
$$

From NPCMs $A_{1}^{1}, A_{2}^{1}, A_{2}^{2}, A_{2}^{3}, A_{2}^{4}$ and $A_{2}^{5}$, the local priority vector $P_{k}^{z} \quad\left(z=1,2, \ldots, n_{k}\right.$, $k=1,2, \ldots, m-1) \quad$ can be yielded using model (1), which listed in the following:

$P_{1}^{1}=(0.3245,0.3101,0.0458,0.1799,0.1397)^{T}$,

$P_{2}^{1}=(0.4272,0.0759,0.2878,0.0662,0.0802,0.0623)^{T}$,

$P_{2}^{2}=(0.3391,0.1097,0.0820,0.0460,0.2201,0.2031)^{T}$,

$P_{2}^{3}=(0.0532,0.1960,0.1847,0.3441,0.1731,0.0490)^{T}$,

$P_{2}^{4}=(0.4045,0.1514,0.0405 .0 .0413,0.1374,0.2249)^{T}$,

$P_{2}^{5}=(0.3989,0.1791,0.0366,0.1113,0.1535,0.1206)^{T}$.

Subsequently, a global priority vector can be generated by synthesizing the local priority vectors using Eq. (4). The global priority vector of alternatives is listed below:

$$
w=(0.3787,0.1186,0.14,0.0739,0.1474,0.1413)^{T}
$$

Then the ranking of alternatives can be derived from $w$ : Electric power generation $>$ Tourism recreation $>$ River traffic $>$ Flood protection $>$ Irrigation $>$ Water supply.

\section{Simulation and comparison analysis}

In this section, we present simulation and comparison analysis to discuss the validity of our proposal. Specifically, the comparison criteria are presented. Then, the simulation method is designed. Finally, the comparison results are analyzed.

\subsection{Comparison criteria}

The consistency is the basics of the preference relations, and we hope that the NPCMs transformed from the corresponding LPCMs are as consistent as possible. Thus, the consistency index of the transformed NPCM is an important criterion to evaluate the decision efficiency of the AHP model. The Saaty's consistency index and geometric consistency index have been widely used in the AHP. Therefore, we use these two consistency indexes to measure the consistency level of transformed NPCM. Moreover, the deviation between a NPCM and its priority vector should be as smaller as possible. Thus, we define the deviation between a NPCM and its priority vector as a comparison criterion. The Euclidean distance and Manhattan distance have been widely used in decision making models, so we use these two distance measures to compute the deviation between a NPCM and its priority vector. Saaty's consistency index has been introduced in Section 2. In the following, we present the geometric consistency index, Euclidean distance between a NPCM and its priority vector, and Manhattan distance between a NPCM and its priority vector.

(1) Geometric consistency index

Let $A=\left(a_{i j}\right)_{n \times n}$ be a NPCM, and $P=\left(p_{1}, \ldots, p_{n}\right)^{T}$ be the priority vector obtained from $A$. Crawford and Williams [9] proposed the geometric consistency index ( $G C I$ ) for measuring the consistency level of the NPCM $A=\left(a_{i j}\right)_{n \times n}$ :

$$
G C I(A)=\frac{2}{(n-1)(n-2)} \sum_{i<j}\left(\log \left(a_{i j}\right)+\log \left(p_{j}\right)-\log \left(p_{i}\right)\right)^{2}
$$

Clearly, $G C I(A) \geq 0 . G C I(A)=0$ indicates that the NPCM $A$ is a completely consistent NPCM. The smaller $G C I(A)$ value signifies the better consistency level of the NPCM $A$.

(2) Euclidean distance between a NPCM and its priority vector

The Euclidean distance [10], $E D$, between the NPCM $A$ and its priority vector $P$ is computed by:

$$
E D(A)=\frac{1}{n} \sqrt{\sum_{j=1}^{n} \sum_{i=1}^{n}\left(a_{i j}-\frac{p_{i}}{p_{j}}\right)^{2}}
$$

Clearly, $E D(A) \geq 0 . E D(A)=0$ indicates that the priority vector $P$ is completely consistent with the NPCM $A$. The smaller $E D(A)$ value indicates the better efficiency of the AHP model.

(3) Manhattan distance between a NPCM and its priority vector

The Manhattan distance, $M D$, between $A$ and 
$P$ is calculated by:

$$
M D(A)=\frac{1}{n^{2}} \sum_{i=1}^{n} \sum_{j=1}^{n}\left|\log \left(a_{i j}\right)-\log \left(\frac{p_{i}}{p_{j}}\right)\right|
$$

Clearly, $M D(A) \geq 0 . M D(A)=0$ indicates that the priority vector $P$ is completely consistent with the NPCM $A$. The smaller $M D(A)$ value indicates the better efficiency of the AHP model.

\subsection{Simulation method}

In this section, we design simulation experiment to compare our proposal with the AHP with a fixed numerical scale (FNS) (i.e., the Saaty's numerical scale). The basic idea of the simulation method is as follows:

We randomly and uniformly generate the LPCMs on a given hierarchical structure based on the linguistic term set $S^{A H P}=\left\{s_{0}, s_{1}, \ldots, s_{16}\right\}$. Then, we take the generated LPCMs as the inputs of our proposal (i.e., the AHP with the PIS) and the AHP with the FNS, and we can obtain the average values of $C R, G C I, E D$, and $M D$ for all NPCMs (i.e., $A C R, A G C I, A E D$ , and $A M D$ ) under these two approaches, respectively.

The simulation method is presented in Table 12 .

Table 12. Simulation method

Input: $m, n_{k} \quad(k=1, \ldots, m-1), n_{k}^{z} \quad\left(z=1, \ldots, n_{k}\right.$; $k=1, \ldots, m-1)$.

Output: $A C R^{(\mathrm{PIS})}, A G C I^{(\mathrm{PIS})}, A E D^{(\mathrm{PIS})}, A M D^{(\mathrm{PIS})}$, $A C R^{(\mathrm{FNS})}, A G C I^{(\mathrm{FNS})}, A E D^{(\mathrm{FNS})}, A M D^{(\mathrm{FNS})}$ values.

Step 1: Based on the established hierarchical structure, we generate $\quad \sum_{k=1}^{m-1} n_{k} \quad$ LPCMs $\quad L_{k}^{z}=\left(l_{i j}^{k, z}\right)_{n_{k}^{z} \times n_{k}^{z}} \quad\left(z=1, \ldots, n_{k}\right.$; $k=1, \ldots, m-1) \quad$ with weak stochastic transitivity, where $l_{i j}^{k, z}$ is uniformly and randomly selected from $S^{\mathrm{AHP}}$.

Step 2: Taking the generated LPCMs $L_{k}^{z}=\left(l_{i j}^{k, z}\right)_{n_{k}^{z} \times n_{k}^{z}}$ $\left(z=1, \ldots, n_{k} ; k=1, \ldots, m-1\right)$ as the inputs of model (14), we can obtain the optimal objective value $M^{*}$. Then, model (20) is used to find the unique individual numerical scales $N S^{\mathrm{AHP}}\left(s_{i}\right) \quad(i=0,1,2, \ldots, 16)$. Following this, we can transform the LPCMs $L_{k}^{z}$ into NPCMs $A_{k}^{z}=\left(a_{i j}^{k, z}\right)_{n_{k}^{z} \times n_{k}^{z}}$ using the obtained individual numerical scales $N S^{\mathrm{AHP}}\left(s_{i}\right)$ $(i=0,1,2, \ldots, 16)$. Subsequently, we utilize model (1) to yield the priority vector $P_{k}^{z}$ from the corresponding NPCM $A_{k}^{z}$. Meanwhile, $C R\left(A_{k}^{z}\right), \quad G C I\left(A_{k}^{z}\right), \quad E D\left(A_{k}^{z}\right), \quad M D\left(A_{k}^{z}\right)$ can be obtained. Finally, we calculate the average value of $C R\left(A_{k}^{z}\right), G C I\left(A_{k}^{z}\right), E D\left(A_{k}^{z}\right), M D\left(A_{k}^{z}\right)$ for all NPCMs, that are

$$
\begin{aligned}
& A C R^{(\mathrm{PIS})}=\sum_{k=1}^{m-1} \sum_{z=1}^{n_{k}} C R\left(A_{k}^{z}\right) / \sum_{k=1}^{m-1} n_{k}, \\
& A G C I^{(\mathrm{PIS})}=\sum_{k=1}^{m-1} \sum_{z=1}^{n_{k}} G C I\left(A_{k}^{z}\right) / \sum_{k=1}^{m-1} n_{k}, \\
& A E D^{(\mathrm{PIS})}=\sum_{k=1}^{m-1} \sum_{z=1}^{n_{k}} E D\left(A_{k}^{z}\right) / \sum_{k=1}^{m-1} n_{k}, \\
& A M D^{(\mathrm{PIS})}=\sum_{k=1}^{m-1} \sum_{z=1}^{n_{k}} M D\left(A_{k}^{z}\right) / \sum_{k=1}^{m-1} n_{k} .
\end{aligned}
$$

Step 3: Using the fixed numerical scale, $N S^{A H P}\left(s_{i}\right)=\left\{\begin{array}{l}1 /(9-i), i=0,1, \ldots, 8 \\ i-7, i=9,10, \ldots, 16\end{array}, \quad\right.$ transforms $\quad$ the LPCMs $L_{k}^{z}$ into NPCMs $A_{k}^{z}$. Subsequently, utilize model (1) to yield the priority vector $P_{k}^{z}$ from NPCM $A_{k}^{z}$. Meanwhile, $C R\left(A_{k}^{z}\right), \quad G C I\left(A_{k}^{z}\right), \quad E D\left(A_{k}^{z}\right), \quad M D\left(A_{k}^{z}\right)$ can be obtained. Finally, we calculate the average values of $C R\left(A_{k}^{z}\right), G C I\left(A_{k}^{z}\right), E D\left(A_{k}^{z}\right), M D\left(A_{k}^{z}\right)$ for all NPCMs, that are $A C R^{(\mathrm{FNS})}=\sum_{k=1}^{m-1} \sum_{z=1}^{n_{k}} C R\left(A_{k}^{z}\right) / \sum_{k=1}^{m-1} n_{k}$,

$$
\begin{aligned}
& A G C I^{(\mathrm{FNS})}=\sum_{k=1}^{m-1} \sum_{z=1}^{n_{k}} G C I\left(A_{k}^{z}\right) / \sum_{k=1}^{m-1} n_{k}, \\
& A E D^{(\mathrm{FNS})}=\sum_{k=1}^{m-1} \sum_{z=1}^{n_{k}} E D\left(A_{k}^{z}\right) / \sum_{k=1}^{m-1} n_{k}, \\
& A M D^{(\mathrm{FNS})}=\sum_{k=1}^{m-1} \sum_{z=1}^{n_{k}} M D\left(A_{k}^{z}\right) / \sum_{k=1}^{m-1} n_{k} .
\end{aligned}
$$

Step 4: Output $A C R^{(\mathrm{PIS})}, A G C I^{(\mathrm{PIS})}, A E D^{(\mathrm{PIS})}$, $A M D^{(\mathrm{PIS})}, A C R^{(\mathrm{FNS})}, A G C I^{(\mathrm{PIS})}, A E D^{(\mathrm{FNS})}$, and $A M D^{(\mathrm{FNS})}$

\subsection{Comparison results}

In this section, we set different parameter values for the simulation method to analyze the performance of our proposal.

We consider a hierarchical structure with three levels: goal level, criterion level and alternative level. In this case, $m=3$, and $n_{1}=1$. Let $\Delta=0.4$, when 


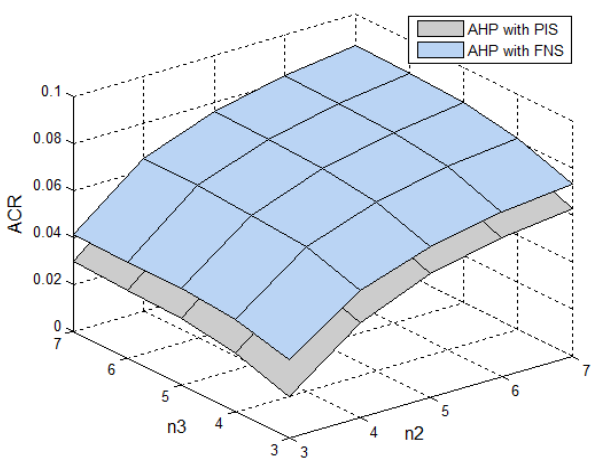

Fig. 5 Average ACR value

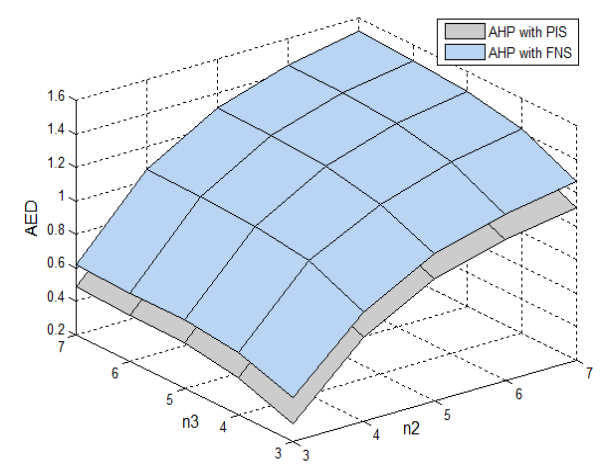

Fig. 7 Average AED value

setting different $n_{2}$ and $n_{3}$ values as the inputs of the simulation method, and we run it 1000 times to generate the average values of $A C R, A G C I, A E D$, and $A M D$ under our proposed approach (i.e., AHP with the PIS) and the existing AHP approach (i.e., AHP with the FNS), respectively, which are described in Figs. 5-8.

From Figs. 5-8, we have the following observations.

The Saaty's consistency index and geometric consistency index of the transformed NPCM, the Manhattan distance and Euclidean distance between a NPCM and its priority vector in the AHP with the PIS are obviously lower than those in the AHP with the FNS, respectively. This finding implies that the proposed approach can improve the decision efficiency by taking the PIS into account.

\section{Conclusion}

In the AHP, the PIS is an important factor that cannot be ignored due to its influence on the final decision results.

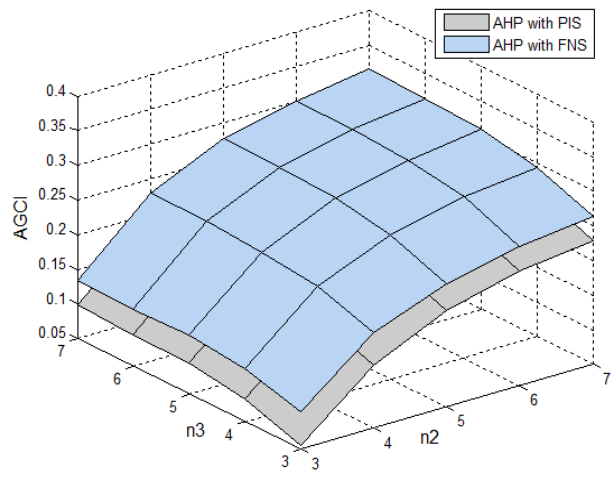

Fig. 6 Average AGCI value

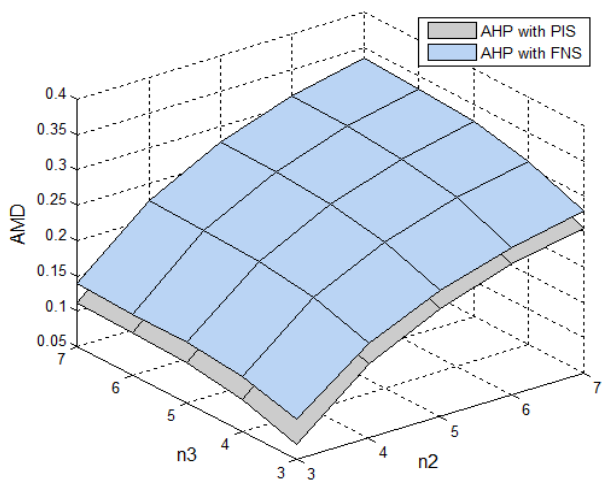

Fig. 8 Average AMD value

This study proposes an AHP framework based PIS for supporting the decision making. The main work of this paper is summarized as follows:

(1) For implementing the computation process, in the AHP the linguistic preference information is often transformed into the numerical preference information using a fixed numerical scale function. In other words, the PIS is not considered by the existing AHP framework. By taking the PIS into account, this study proposes a novel AHP framework, which is closer to the realistic decision scenario.

(2) We develop a consistency-driven approach that minimizes the inconsistency level of the transformed numerical preference information (i.e., multiplicative preference relations) to support the proposed AHP framework. In the consistency-driven approach, a two-stage based optimization model is designed to deal with the PIS, and we transform it into linear programming model that can be easily solved.

(3) We design the detailed simulation experiment to verify the validity of the AHP framework with the PIS, and the simulation results show that our proposal 
has a better decision efficiency compared with the existing AHP framework.

Meanwhile, the following research paths are pointed out for the future:

(1) In our proposal, each element in an LPCM is mapped to an exact number. However, an LPCM is usually with uncertainty. To deal with this issue, the uncertain numerical scale (interval numerical scale) has been proposed and used in the linguistic decision making [19], further studies should discuss the uses of the interval numerical scale in the PIS based AHP framework.

(2) Practical decision making involves both mathematical models and psychological issues (e.g., prospect theory $[17,36])$. However, psychological issues are seldom considered in the existing AHP models. To study the psychological issues of decision maker(s) in the PIS based AHP framework is a very interesting research direction.

(3) In addition, the consensus based group decision making has become a hot topic $[11,18,20]$. It would be interesting in any future research to export the PIS based AHP framework to the consensus based group decision making.

\section{Acknowledgements}

This work was supported by the grant (No. 71571124) from NSF of China, and the grant (No. 2017B07514) from "the Fundamental Research Funds for the Central Universities".

\section{References}

1. S. Alonso, F. Chiclana, F. Herrera, E. Herrera-Viedma, J. Alcalá-Fdez, C. Porcel, A consistency-based procedure to estimate missing pairwise preference values. International Journal of Intelligent Systems 23 (2008) 155-175.

2. J.A. Alonso, M.T. Lamata, Consistency in the analytic hierarchy process: a new approach. International Journal of Uncertainty, Fuzziness and Knowledge-Based Systems 14 (2006) 445-459.

3. J. Aguarón, J.M. Moreno-Jiménez, The geometric consistency index: Approximated thresholds. European Journal of Operational Research 147 (2003) 137-145.

4. E. Blankmeyer, Approaches to consistency adjustments. Journal of Optimization Theory and Applications 54 (1987) 479-488.

5. S. Bozóki, J. Fülöp, W.W. Koczkodaj, An LP-based inconsistency monitoring of pairwise comparison matrices. Mathematical and Computer Modelling 54 (2011) 789-793.

6. M. Brunelli, L. Canal, M. Fedrizzi, Inconsistency indices for pairwise comparison matrices: a numerical study. Annals of Operations Research 211 (2013) 493-509.

7. X. Chen, H.J. Zhang, Y.C. Dong, The fusion process with heterogeneous preference structures in group decision making: A survey. Information Fusion 24 (2015) 72-83.

8. A.T.W. Chu, R.E. Kalaba, K. Spingarn, A comparison of two methods for determining the weights of belonging to fuzzy sets. Journal of Optimization Theory and Applications 27 (1979) 531-538.

9. G. Crawford, C. Williams, A note on the analysis of subjective judgement matrices. Journal of Mathematical Psychology 29 (1985) 387-405.

10. R. Degani, G. Bortolan, The problem of linguistic approximation in clinical decision making. International Journal of Approximate Reasoning 2 (1988) 143-162.

11. Y.C. Dong, Z.G. Ding, L. Martínez, F. Herrera, Managing consensus based on leadership in opinion dynamics. Information Sciences 397-398(2017) 187-205.

12. Y.C. Dong, E. Herrera-Viedma, Consistency-driven automatic methodology to set interval numerical scales of 2-tuple linguistic term sets and its use in the linguistic GDM with preference relation. IEEE Transactions on Cybernetics 45 (2015) 780-792.

13. Y. C. Dong, W. C. Hong, Y. F. Xu, S. Yu, Numerical scales generated individually for analytic hierarchy process. European Journal of Operational Research 229 (2013) 654-662.

14. Y.C. Dong, C.C. Li, F. Chiclana, E. Herrera-Viedma, Average-case consistency measurement and analysis of interval-valued reciprocal preference relations. Knowledge-based Systems 114 (2016) 108-117.

15. Y.C. Dong, C.C. Li, F. Herrera, Connecting the linguistic hierarchy and the numerical scale for the 2-tuple linguistic model and its uses to deal with hesitant unbalanced linguistic information. Information Sciences 367-368 (2016) 259-278.

16. Y.C. Dong, C.C. Li, Y.F. Xu, X. Gu, Consensus-based group decision making under multi-granular unbalanced 2-tuple linguistic preference relations. Group Decision and Negotiation 24 (2015) 217-242.

17. Y.C. Dong, Y.T. Liu, H.M. Liang, F. Chiclana, E. Herrera-Viedma, Strategic weight manipulation in multiple attribute decision making. Omega 75 (2018) 154-164.

18. Y.C. Dong, M. Zhan, G. Kou, Z.G. Ding, H.M. Liang, A survey on the fusion process in opinion dynamics. Information Fusion 43 (2018) 57-65.

19. Y.C. Dong, G.Q. Zhang, W.C. Hong, S. Yu, Linguistic computational model based on 2-tuples and intervals. IEEE Transactions on Fuzzy Systems 21 (2013) 10061018.

20. Y.C. Dong, H.J. Zhang, E. Herrera-Viedma, Consensus reaching model in the complex and dynamic MAGDM problem. Knowledge-based Systems, $106 \quad$ (2016) 
206-219.

21. J.S. Finan, W.J. Hurley, Transitive calibration of the AHP verbal scale. European Journal of Operational Research 112 (1999) 367-372.

22. Z.W. Gong, C.L. Guo, Y.Y. He, Group decision making methods of the incomplete IFPRs and IPRs. International Journal of Computational Intelligence Systems 5 (2012) $542-552$.

23. P.T. Harker, L.G. Vargas, The theory of ratio scale estimation: Saaty's analytic process. Management Science 33 (1987) 1383-1403.

24. F. Herrera, L. Martínez, A 2-tuple fuzzy linguistic representation model for computing with words. IEEE Transactions Fuzzy System 8 (2000) 746-752.

25. E.K.R.E. Huizingh, H.C.J. Vrolijk, A comparison of verbal and numerical judgments in the analytic hierarchy process. Organizational Behavior and Human Decision Processes 70 (1997) 237-247.

26. P. Ji, R. Jiang, Scale transitivity in the AHP. The Journal of the Operational Research Society 54 (2003) 896-905.

27. C.C. Li, Y.C. Dong, F. Herrera, E. Herrera-Viedma, L. Martínez, Personalized individual semantics in computing with words for supporting linguistic group decision making. An application on consensus reaching. Information Fusion 33 (2017) 29-40.

28. W.Q. Liu, Y.C. Dong, F. Chiclana, F.J. Cabrerizo, E. Herrera-Viedma, Group decision-making based on heterogeneous preference relations with self-confidence. Fuzzy Optimization and Decision Making 16 (2017) 429-447.

29. F.A. Lootsma, Scale sensitivity in the multiplicative AHP and SMART. Journal of Multi-Criteria Decision Analysis 2 (1993) 87-110.

30. D. Ma, X. Zheng, 9/9-9/1 Scale method of AHP. In: Proceeding of the Second International Symposium on the AHP. University of Pittsburgh, Pittsburgh, PA (1991) 197-202.

31. J. Mendel, D. Wu, Perceptual computing: Aiding people in making subjective judgments. John Wiley \& IEEE Press (2010).

32. J.M. Mendel, L.A. Zadeh, E. Trillas, R.R. Yager, J. Lawry, H. Hagras, S. Guadarrama, What computing with words means to me: Discussion forum. IEEE Computational Intelligence Magazine 5 (2010) 20-26.

33. L. Mikhailov, A fuzzy programming method for deriving priorities in the analytic hierarchy process. Journal of the Operational Research Society 51 (1997) 341-349.

34. J.A. Morente-Molinera, I.J. Pérez, M.R. Urea, E. Herrera-Viedma, On multi-granular fuzzy linguistic modeling in group decision making problems: a systematic review and future trends. Knowledge-Based Systems 74 (2015) 49-60.

35. M.A. Poyhonen, R.P. Hämäläinen, A.A. Salo, An experiment on the numerical modeling of verbal ratio statements. Journal of Multicriteria Decision Analysis 6 (1997) 1-10.

36. R. Rosenman, R. Fort, W. Budd, Perceptions, fear, and economic loss: an application of prospect theory to environmental decision making. Policy Sciences 21 (1988) 21-327.

37. A.A. Salo, R.P. Hämäläinen, On the measurement of preferences in the analytic hierarchy process. Journal of Multi-Criteria Decision Analysis 6 (1997) 309-319.

38. T.L. Saaty, The analytic hierarchy process. New York: McGrawHill (1980).

39. T.L. Saaty, Eigenvector and logarithmic least squares. European Journal of Operational Research 48 (1980) 156-160.

40. T.L. Saaty, L.G. Vargas, Uncertainty and rank order in the analytic hierarchy process. European Journal of Operational Research 32 (1987) 107-117.

41. B. Srdjevic, Combining different prioritization methods in the analytic hierarchy process synthesis. Computers and Operations Research 32 (2005) 1897- 1919.

42. W.E. Stein, P.J. Mizzi, The harmonic consistency index for the analytic hierarchy process. European Journal of Operational Research 177 (2007) 488-497.

43. O.S. Vaidya, S. Kumar, Analytic hierarchy process: An overview of applications. European Journal of Operational Research 169 (2006) 1-29.

44. G.Q. Zhang, Y.C. Dong, Y.F. Xu, Consistency and consensus measures for linguistic preference relation based on distribution assessment. Information Fusion 17 (2014) 46-55.

45. H.J. Zhang, Y.C. Dong, X. Chen, The 2-rank consensus reaching model in the multigranular linguistic multipleattribute group decision-making. IEEE Transactions on Systems, Man, and Cybernetics: Systems (2017, in press), doi: 10.1109/TSMC.2017.2694429.

46. H.J. Zhang, Y.C. Dong, E. Herrera-Viedma, Consensus building for the heterogeneous large-scale GDM with the individual concerns and satisfactions. IEEE Transactions on Fuzzy Systems (2017, in press), doi: 10.1109/ TFUZZ.2017.2697403.

47. Z. Zhang, C.H. Guo, Consistency and consensus models for group decision-making with uncertain 2-tuple linguistic preference relations. International Journal of Systems Science, 47 (2016), 2572-2587.

48. Z. Zhang, C.H. Guo, Consistency-based algorithms to estimate missing elements for uncertain 2-tuple linguistic preference relations. International Journal of Computational Intelligence Systems, 7(2014), 924-936.

49. Z. Zhang, C.H. Guo, Deriving priority weights from intuitionistic multiplicative preference relations under group decision-making settings. Journal of the Operational Research Society, 68 (2017) 1582-1599

50. Z. Zhang, C. Guo, L. Martínez, Managing multigranular linguistic distribution assessments in large-scale multiattribute group decision making. IEEE Transactions on Systems, Man, and Cybernetics: Systems 47 (2017) $3063-3076$. 